\title{
Frequency and within-type variations of large-scale circulation types and their effects on low-frequency climate variability in Central Europe since 1780
}

\author{
C. Beck, ${ }^{\mathrm{a}, *}$ J. Jacobeit ${ }^{\mathrm{b}}$ and P. D. Jones ${ }^{\mathrm{c}}$ \\ a Global Precipitation Climatology Centre, c/o Deutscher Wetterdienst, P. O. Box 1004 65, D 63004 Offenbach, Germany \\ b Institute of Geography, University of Augsburg, Universitaetsstrasse 10, D 86135 Augsburg, Germany \\ c Climatic Research Unit, School of Environmental Sciences, University of East Anglia, Norwich NR4 7TJ, UK
}

\begin{abstract}
:
This study investigates the importance of large-scale atmospheric circulation changes for Central European climate variations during the last two centuries. On the basis of an objective classification of monthly mean sea level pressure (SLP) grids reconstructed back to 1780 and monthly historical station data for the same period, temperature and precipitation changes in Central Europe since 1780 are decomposed into two parts; one part due to frequency changes of large-scale circulation types, and the other part caused by (dynamic and climatic) changes within these circulation types. This is achieved by applying a particular decomposition scheme for moving 31-year time windows during the 1780-1995 period. Results indicate that large parts of the long-term variations in Central European climate cannot be explained sufficiently by frequency changes of circulation types. Roughly one half of these variations - even up to $80 \%$ during July - can be ascribed to varying internal properties of some major circulation types. Percentages of frequency-related and within-typerelated climate changes are seen to vary on decadal to multidecadal time scales, thus implying that relationships between large-scale circulation patterns and regional climates are characterised by distinct instationarities. Furthermore, regional climate variations, being attributable to within-type changes of major circulation types, can only partly be explained by corresponding variations in dynamic properties (vorticity, intensity) of these circulation types. This points to the importance of further sources for within-type variability, including subgrid-scale processes, synoptic-scale variations, and modifications of the climatic boundary conditions.
\end{abstract}

KEY WORDS objective circulation classification; Großwettertypes; frequency variations; within-type variations; low-frequency climate variations; North Atlantic; Central Europe

\section{INTRODUCTION}

In the context of current discussions concerning recent climate change, including man-made greenhouse forcing, it is essential to extend the investigations on natural climate variability back to historical times since this may provide an improved understanding of the climate system, which is required for the assessment of possible changes in climate that might be expected in the future. The large-scale atmospheric circulation is directly linked to all kinds of regional climate variations. This is true not only for synoptic time scales of several weeks or months, but also for decadal to centennial (and much longer) time scales. Therefore, investigations concerning low-frequency climate variations should not be restricted to parameters like temperature and precipitation but also include dynamics of the atmospheric circulation. This allows the study of not only the links

\footnotetext{
* Correspondence to: C. Beck, Global Precipitation Climatology Centre, c/o Deutscher Wetterdienst, D-63004 Offenbach, Germany.

E-mail: christoph.beck@dwd.de
}

between circulation and climate variability on different temporal and spatial scales but also the variations of circulation-climate relations themselves (provided that sufficiently extended time series are available). This has particular importance because statistical assessments of future regional climate changes from large-scale circulation predictors by means of different downscaling techniques are based on assumptions of stationarity between circulation and climate. Investigating these relations with an extended data base back to historical times may reveal whether stationarity is a reasonable assumption in this context.

Though numerous studies concerning the reconstruction and interpretation of temperature and precipitation data have been carried out for periods going well back into the historical past (for Central Europe see for example Pfister, 1985, 1999; Glaser, 1991, 2001), objective analyses dealing with the low-frequency variability of the atmospheric circulation have mainly been confined to the last century owing to the restricted availability of gridded pressure data (e.g. Barnston and Livezey, 1987; 
Bardossy and Caspary, 1990; Jacobeit, 1993; Corte-Real et al., 1995; Klaus, 1997; Rogers, 1997; Kapala et al., 1998; Mächel et al., 1998; Werner et al., 2000). For earlier periods of the historical past, several authors have worked on subjective reconstructions and analyses of North Atlantic-European surface pressure fields (e.g. Lamb and Johnson, 1959, 1961; Kington, 1988; Wanner et al., 1994; Jacobeit et al., 1999). Jones et al. (1987) were the first investigators to provide gridded monthly mean SLP data for the North Atlantic-European region back to 1780 on the basis of an objective reconstruction technique. The resulting data set gave rise to an initial objective circulation analysis covering a period of more than 200 years (Schmutz and Wanner, 1998). On the basis of an improved version of these gridded SLP data back to 1780 (Jones et al., 1999b), several investigations in the context of the European climate research project ADVICE (Annual to Decadal Variability in Climate in Europe) have been carried out during recent years (e.g. Beck, 2000; Beck et al., 2001; Jacobeit et al., 1998, 2001a,b). These investigations include comparative synoptic analyses between an early instrumental period (1780-1860) and the 20th century (Beck, 2000), investigations on long-term circulation variability mainly based on PCA-derived major SLP patterns (Jacobeit et al., 2001a; Beck et al., 2001), and studies on relationships between zonal indices and Central European temperatures since 1780 (Jacobeit et al., 2001b). As a result, strong variations in circulation-climate relationships were indicated. This is in agreement with the evidence that the construction of observed climate variations exclusively from largerscale circulation predictors often show poor levels of skill (e.g. Werner and von Storch, 1993; Beck, 2000). This points to the dynamic phenomena that have been addressed as 'within-type changes' (Barry and Perry, 1973; Brinkmann, 1999) and refers to those parts of climate variations that cannot be explained by frequency changes of atmospheric circulation types and have to be attributed to changing characteristics of the types themselves.

The present study takes up this approach in analyzing Central European temperature and precipitation since 1780 in terms of North Atlantic-European circulation dynamics, including both frequency and within-type changes of the atmospheric circulation. In contrast to earlier studies ( $o p c i t$ ), analyses are based neither on simple circulation indices nor on PCA-derived circulation patterns, but on an objective pressure field classification associated with the so-called European Großwettertypes (see Section 3.1). Temperature and precipitation changes in Central Europe since 1780 are decomposed into varying parts attributable to changing circulation type frequencies on the one hand and within-type changes of these circulation types on the other. This paper will focus on January, April, July and October, thus comprising selected months from all the four seasons.

Another SLP reconstruction that even goes back (with monthly resolution) to the mid-17th century is available
(Luterbacher et al., 2002a). On the basis of these data, several papers dealing with historical circulation analyses have been published (Luterbacher et al., 2001, 2002b; Jacobeit et al., 2003). However, these papers do not address relationships between circulation and climate as these reconstructions make use of temperature and precipitation data. So, we restrict our study to the SLP reconstructions by Jones et al. (1999b). The study period (since 1780) still includes the later decades of the socalled Little Ice Age (LIA), when man-made impacts on climate were still negligible. However, the last century of the study period represents conditions of increased climate forcing by human activities. Thus, the whole period of study includes quite distinct periods involving man's impact on climate, potentially allowing us to assess whether this implies any specific changes in circulation-climate relationships.

\section{DATA}

\subsection{Monthly temperature and precipitation time series for Central Europe}

Twenty-six temperature and 39 precipitation series, with data back to the year 1780, have been extracted from different data sources (World Climate Disc, 1992; Schönwiese and Rapp, 1997; archive of the German Weather Service). Figure 1 shows the spatial distribution of these station time series. All of them have been tested for homogeneity by applying several statistical tests to the annual series, in particular, the Alexandersson test for single shifts in the mean (Alexandersson, 1986). Significant inhomogeneities (95\% confidence level) have been homogenized according to Böhm (1992) on the basis of the monthly series (see Beck (2000) for a more detailed description of testing methods and the homogenisation procedure). Not all series have complete records for the whole period. Data availability, in terms of percentages of temperature (precipitation) series with monthly data, increases from roughly $65 \%(16 \%)$ in 1780 to approximately $80 \%(35 \%)$ in 1810. From around 1830 (1850) onwards, monthly data are available from all temperature (precipitation) series.

As recommended by Jones and Hulme (1996), missing values within the individual station time series have been interpolated by using normalized anomaly fields by referring to one common 30-year reference period (1961-1990). Central European time series of temperature and precipitation, as displayed in Figure 2, have been calculated as simple spatial averages of the corresponding station time series.

\subsection{Reconstructed monthly mean SLP grids for the North Atlantic-European area}

Analyses of the atmospheric circulation are based on gridded monthly mean SLP data for the North AtlanticEuropean area, which have been reconstructed back to 1780 by Jones et al. (1999b). The reconstruction is based 


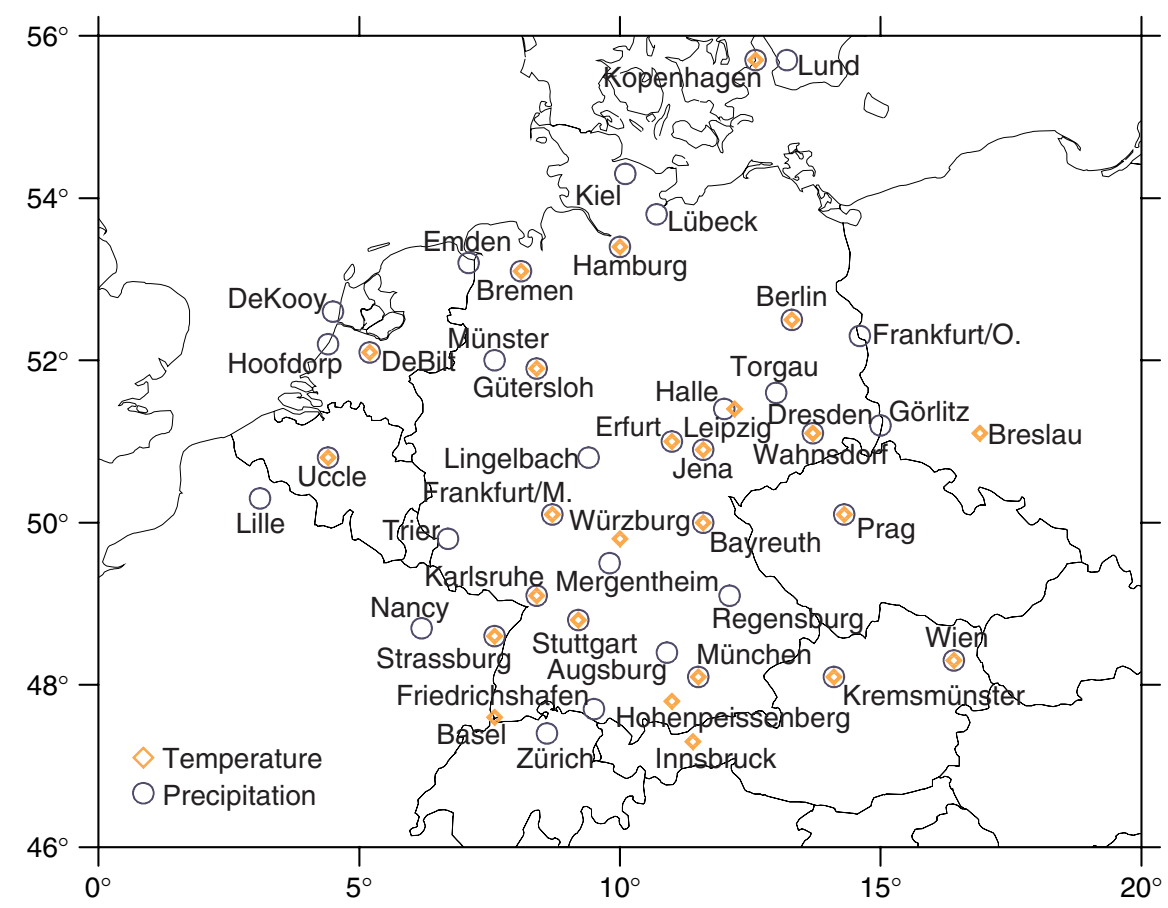

Figure 1. Spatial distribution of Central European temperature and precipitation time series since 1780. This figure is available in colour online at www.interscience.wiley.com/ijoc
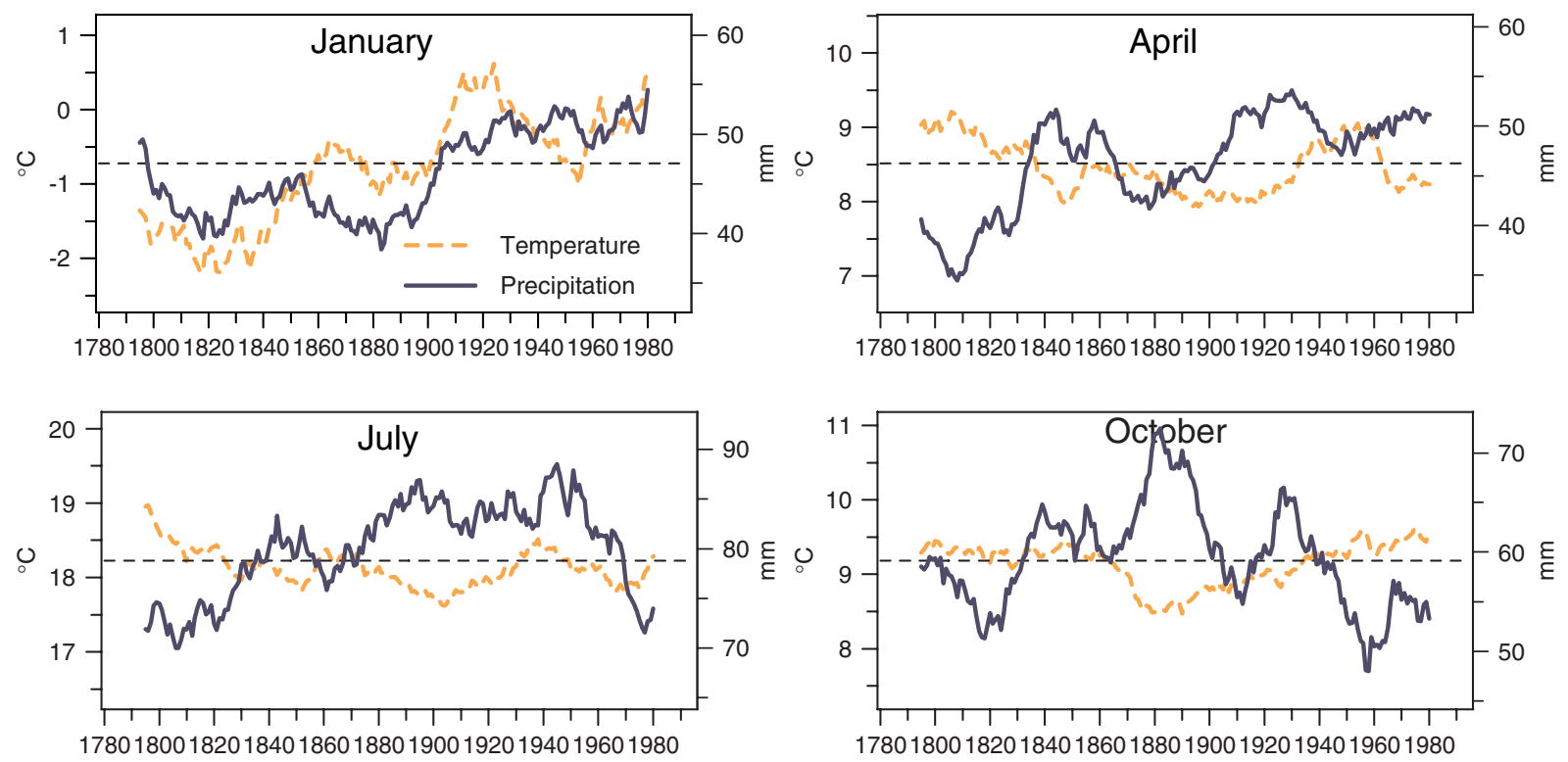

Figure 2. 31-year running means of Central European monthly temperature $\left({ }^{\circ} \mathrm{C}\right)$ and precipitation $(\mathrm{mm})$. Dashed lines indicate the long-term means, 1780-1995. This figure is available in colour online at www.interscience.wiley.com/ijoc

on homogenized long-term station pressure time series and was developed by means of EOF-multiple-regression models that generated SLP fields on a $5^{\circ}$ latitude by $10^{\circ}$ longitude grid covering the region from 35 to $70^{\circ} \mathrm{N}$ and from $30^{\circ} \mathrm{W}$ to $40^{\circ} \mathrm{E}$. The available station network starts with 10 stations having continuous pressure time series since 1780 , and the number increases to 51 stations by the middle of the 19th century. The EOF-regression models for deriving gridded SLP data were calibrated over the 1936-1995 period and verified using the 1881-1935 period. Best model results, in terms of explained variances, were obtained for the central gridpoints and during the periods with the most extensive station network. Explained variances decrease towards the grid's periphery and with the diminution of the station network during earlier times. Generally, better results were obtained during winter than during the summer months (Jones et al., 1999b). In spite of these minor restrictions, the 
SLP grids provide an appropriate basis for studies concerning atmospheric circulation variability during periods that are not covered by commonly available SLP data sets.

\section{METHODS}

\subsection{Objective classification of monthly mean SLP grids since 1780}

A new objective pressure pattern classification was applied to the reconstructed monthly mean SLP grids since 1780. The general purpose of SLP classification is to identify an adequate and relatively small number of representative SLP patterns that are expected to reproduce the essential circulation features of all individual SLP fields (El-Kadi and Smithson, 1992; Yarnal, 1993; Huth, 1996). Various circulation classifications have proved to be appropriate for analysing low-frequency variability of the large-scale atmospheric circulation (e.g. Bardossy and Caspary, 1990; Klaus, 1997; Schmutz and Wanner, 1998). Besides the well-known subjective classifications for the North Atlantic-European area, like the British Isles weather types (Lamb, 1950) or the so-called Central European Großwettertypes (Hess and Brezowski, 1952; Gerstengarbe and Werner, 1993), there are a large number of objective approaches to classify large-scale patterns of the atmospheric circulation. The most frequently used techniques include correlation-based classifications on the one hand (e.g. Lund, 1963; Kirchhofer, 1973; Schmutz and Wanner, 1998) and algorithms based on EOF and cluster analyses on the other (e.g. Kruizinga, 1979; Yarnal, 1993; Huth, 1996; Beck, 2000). Dittmann et al. (1995) developed an objective weather-type classification for the Central European region, with predefined threshold values for several parameters describing circulation dynamics and humidity characteristics at the 950 and $500 \mathrm{hPa}$ levels used for partitioning. In contrast to the subjective classifications, all the objective ones produce results that can be reproduced if all the internal and subjective choices of parameter settings are known.

The major drawback of computer-assisted classification schemes is the fact that resulting patterns frequently do not reproduce some of the well-known major circulation modes in a satisfying manner. One way to overcome this problem is to use predefined circulation patterns as key patterns for a subsequently automated classification procedure of the individual SLP fields. Such an approach has been applied, for example, by Frakes and Yarnal (1997) who at first determined, subjectively, key patterns of geopotential height fields and subsequently classified all individual fields by means of a correlation-based classification algorithm referring to the key patterns.

Another classification approach has been developed by Beck (2000): it is based on predefined circulation patterns determined according to the subjective classification of the so-called Central European Großwettertypes (Hess and Brezowski, 1952; Gerstengarbe and Werner, 1993). It is assumed that these 10 Großwettertypes - resulting from a generalization of 29 large-scale weather patterns defined by the geographical position of major centres of action and the location and extension of frontal zones (Gerstengarbe and Werner, 1993) - can be sufficiently characterized in terms of varying degrees of zonality, meridionality, and vorticity of the large-scale SLP field over Europe. On the basis of this assumption, the classification scheme consists of the following steps (Beck, 2000):

- At first, three prototypical SLP patterns are defined for the region $10^{\circ} \mathrm{W}-30^{\circ} \mathrm{E}$ and $40^{\circ} \mathrm{N}-60^{\circ} \mathrm{N}$ - thus including 25 grid points - representing idealized $\mathrm{W}-\mathrm{E}, \mathrm{S}-\mathrm{N}$, and central low-pressure isobars over this European region.

- Spatial correlations with these prototypical patterns are calculated for all monthly mean SLP grids for $1780-1995$ on the basis of the central 25-grid-point area; they will be addressed as coefficients of zonality $(\mathrm{Z})$, meridionality $(\mathrm{M})$, and vorticity $(\mathrm{V})$, respectively.

- The ten Central European Großwettertypes are defined by means of particular combinations of these three correlation coefficients: Großwettertypes' high and low pressure over Central Europe result from a maximum $\mathrm{V}$ coefficient (negative and positive, respectively). The remaining eight main circulation types are defined in terms of the $\mathrm{Z}$ and $\mathrm{M}$ coefficients corresponding to the main isobar directions over central Europe (e.g. $Z=1$ and $\mathrm{M}=0$ for the $\mathrm{W}-\mathrm{E}$ pattern, $\mathrm{Z}=0.7$ and $\mathrm{M}=0.7$ for the SW-NE pattern, and so on). Each monthly SLP grid outside the high- and low-pressure samples is assigned to one of these direction types according to the minimum Euclidean distance of its $\mathrm{Z}$ and $\mathrm{M}$ coefficients from those of the predefined prototypes.

- A further subdivision of these eight circulation type samples into cyclonic and anticyclonic subsamples is achieved according to the sign of the corresponding $\mathrm{V}$ coefficient.

Finally, 18 representative SLP patterns are obtained by averaging all monthly SLP grids of the 1780-1995 period, which are assigned to the same circulation type, respectively (Figure 3 ).

\subsection{Frequency and within-type changes of circulation types}

Frequencies of North Atlantic-European circulation types are calculated for moving 31-year periods using annual time steps. This interval is close to the length of 'climate normals' and as they change a year at a time, they can be considered as 'running normals'.

Within-type changes may be assigned to two different groups: the first one comprises climate characteristics that are linked to the occurrence of a particular circulation type; here we use the Central European temperature and precipitation data to describe changes in climate linked to the occurrence of each of these circulation types, respectively. The second group refers to dynamic properties changing within each of these types; here 

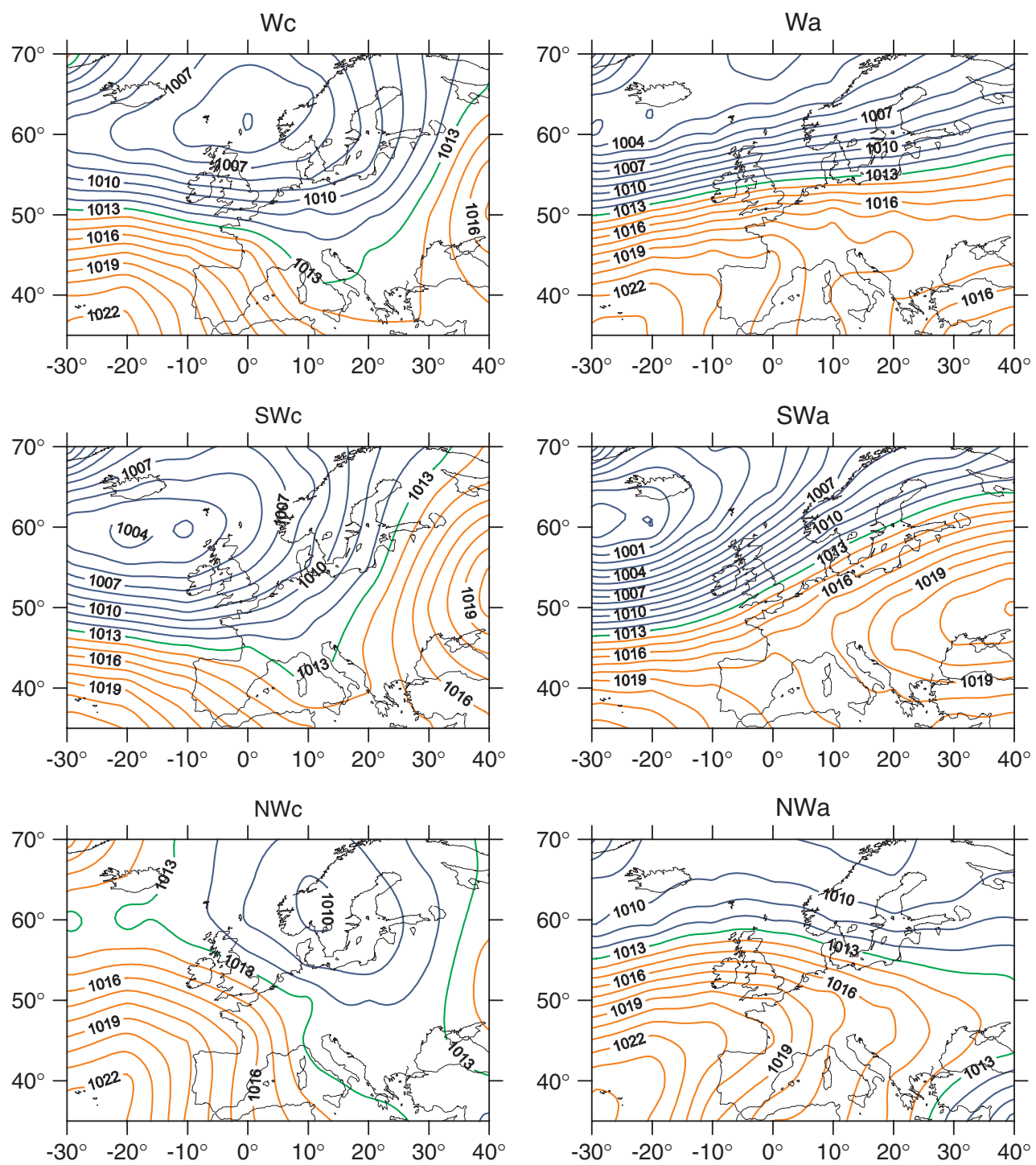

Figure 3. SLP composites of objectively derived circulation types for 1780-1995 (lower case letters "c" and "a" denote cyclonic and anticyclonic subtypes respectively). This figure is available in colour online at www.interscience.wiley.com/ijoc

we consider the varying pressure gradients and vorticity conditions over Europe representing important parts of such dynamic changes. Pressure gradients are determined between the moving SLP centres of action, separately for each circulation type; as a simple vorticity index the $\mathrm{V}$ coefficient (see Section 3.1) is used. All within-type parameters are calculated for moving 31-year periods with annual time steps, corresponding to the frequency changes mentioned above.

\subsection{Decomposition of climate changes into particular parts due to frequency and within-type changes of atmospheric circulation types}

Barry and Perry, 1973 (p. 374 ff.) offered a simple method to decompose a climate difference $\Delta \bar{C}$ between two periods into different parts that are caused by frequency and within-type changes of circulation types:

$$
\Delta \bar{C}=\sum_{i=1}^{G}\left[\left(\Delta F_{i}\left(C_{i}+\Delta C_{i}\right) / n+F_{i} \cdot \Delta C_{i} / n\right]\right.
$$

where

$G=$ number of circulation types

$F_{i}=$ frequency of circulation type $i$ during the first period

$F_{i}+\Delta F_{i}=$ frequency of circulation type $i$ during the second period

$n=$ number of time units during the first period

$C_{i}=$ climatic mean of circulation type $i$ during the first period

$C_{i}+\Delta C_{i}=$ climatic mean of circulation type $i$ during the second period

The expression $[\Delta F i(C i+\Delta C i) / n]$ describes the change in climate between the two periods due to frequency changes of circulation type $i$, whereas $[F i$. 

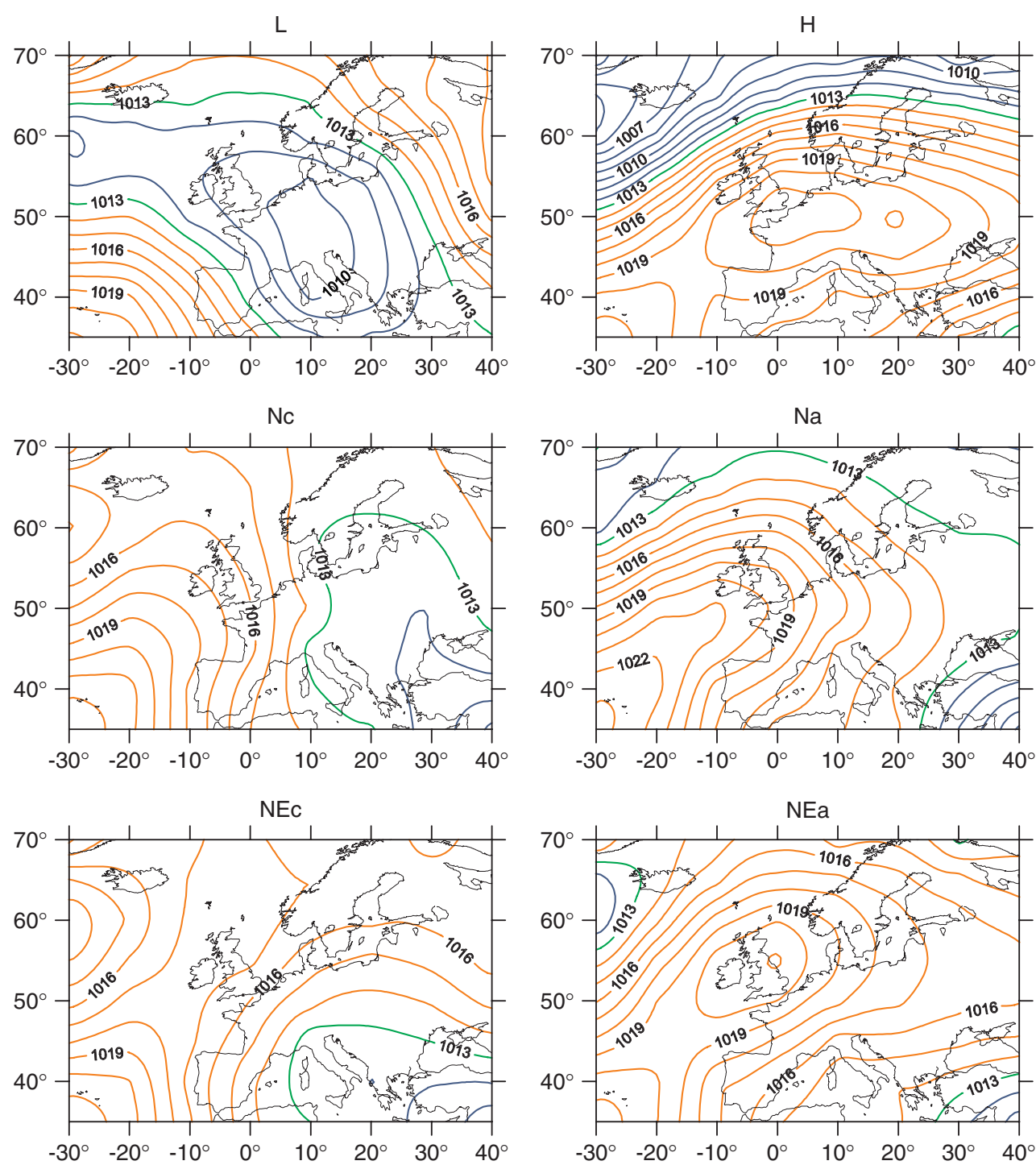

Figure 3. (Continued)

$\Delta C i / n]$ depicts the degree of climate change that has to be assigned to a modified climate linked with circulation type $i$.

Beck (2000) has used this method to compare the 1780-1860 and 1915-1995 periods with respect to climate change due to frequency and within-type changes of particular circulation types. In contrast to this fixedperiod approach, results of this study are based on moving 31-year time windows, with annual time steps covering the whole period from 1780 to 1995 in such a way that each of the 31-year periods is compared the next 31-year time window shifted by one year. Thus, the continuous changes in Central European climate due to frequency and within-type changes of the atmospheric circulation will be recorded for more than 200 years.

\section{RESULTS}

Analyses have been performed for all months of the year referring to both temperature and precipitation change in Central Europe. This paper will focus on the central months of each season: January, April, July, and October.

\subsection{Central European temperature and precipitation variability since 1780}

This section only describes the general background of climate variability for the subsequent analyses dealing with circulation-climate relationships. Time series of Central European temperature and precipitation (moving averages of 31-year time windows with annual time steps, see Figure 2) reveal marked decadal-scale variations during the whole study period. The most outstanding feature in January is the well-known long-term increase of both parameters, with a general change from below-average to above-average values around 1900 . In contrast to that, April exhibits decreasing temperatures until 1900, with shorter-term variations and trends afterwards. Precipitation often shows opposite deviations from the long-term mean compared to temperature. July is similar to April, except that during recent decades there is a marked decline in precipitation. During October, temperature and 
Ec
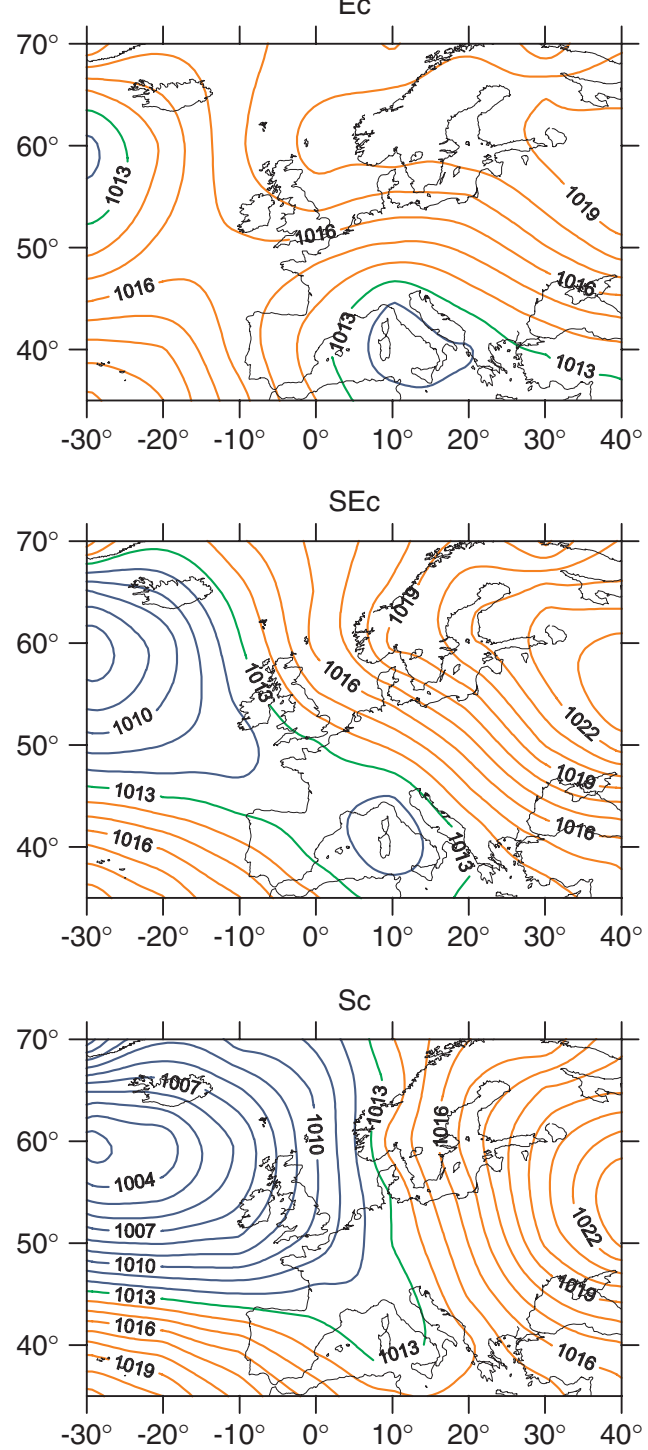
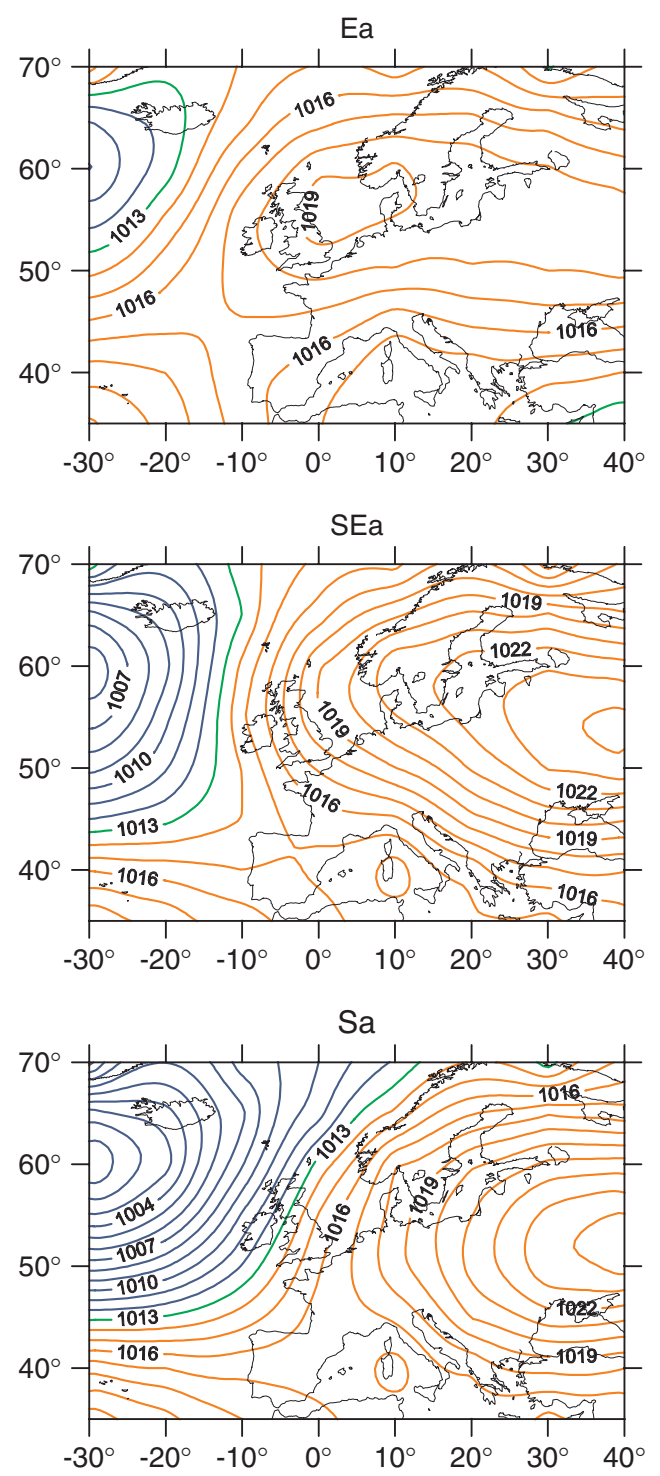

Figure 3. (Continued).

precipitation are essentially uncoupled: a long-term thermal increase since about 1880 is combined with the most pronounced decadal-scale variations in precipitation (Figure 2). As for seasonal contrasts, the pre-1900 period had a more continental-type climate (cold winters, warm summers) than the more recent period (1965-1995, Beck, 2000).

\subsection{Central European Großwettertypes 1780-1995}

The SLP composites of the objectively classified Großwettertypes (Figure 3) represent the major circulation types in the North Atlantic-European region. The ten main types are well defined according to the direction of their isobars, including high or low pressure centred over Europe. Obviously, the distinction into cyclonic and anticyclonic subtypes reproduces important differences in circulation patterns with respect to Central Europe. Note, however, that the airflow direction near the surface cannot be derived directly from the orientation of the isobars owing to frictional forces from the earth's surface (typical deviations amount to 15-30 degrees). Thus, airflow directions do not strictly correspond to those used for the designation of circulation types. This minor restriction, however, does not affect the method of classification itself.

Percentage frequencies of the 10 main circulation types during the whole year (Figure 4) reflect the dominance of westerly airflow directions for Central Europe. The three most frequent types attain a cumulative frequency of about 69\% (W, 28.4\%; NW, 20.3\%; SW, 20.3\%). Looking at the selected months (Figure 4), January and October are clearly dominated by westerly and southwesterly types (W, 35.7\% and SW, 33.8\% for January; SW, 39.4\% and W, 29.6\% for October). In July, the northwesterly type has a large value (NW, 62.0\%). In contrast to these three months, April does not show any clear preponderance of particular circulation types, a situation typical of mid-latitude circulation dynamics during the spring season. 

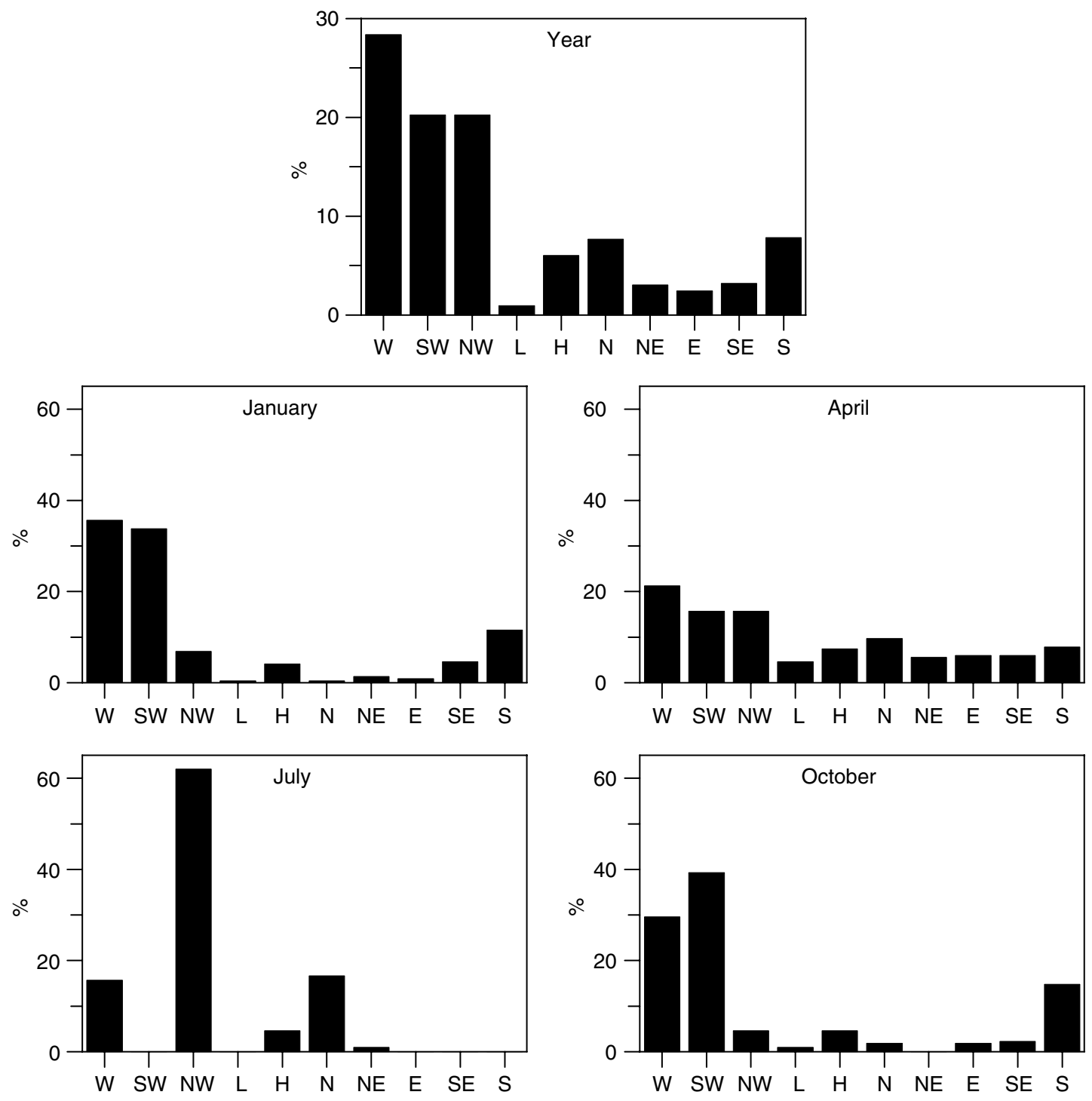

Figure 4. Percentage frequencies of the 10 main circulation types 1780-1995.

\subsection{Circulation changes in relation to Central European climate variability since 1780}

4.3.1. Frequency and within-type changes of the Großwettertype ensemble. Temperature and precipitation differences between consecutive 31-year periods have been decomposed as described in Section 3.3. These differences are transformed into cumulative time series reflecting long-term variations of monthly temperature and precipitation, which may be ascribed to frequency and within-type changes of Central European Großwettertypes, respectively. Figures 5 and 7 illustrate these cumulative time series of temperature and precipitation differences for the frequency-related part, the within-type-related part, and for both of them during the 1780-1995 period. Figures 6 and 8 give the percentage variations of the frequency-related and the within-typerelated part with respect to the whole temperature and precipitation changes, respectively.

Percentages of temperature/precipitation differences between consecutive 31-year periods due to frequency changes and within-type changes of the large-scale circulation types, respectively, have been estimated on the basis of the corresponding absolute values. Accordingly, the absolute values of the combined effect (frequencyinduced and within-type related) of each circulation type have been used to determine the percentages of temperature/precipitation differences that may be attributed to individual circulation types.

Table I summarizes these percentages for the entire period from 1780 to 1995 , revealing that large parts of the climatic variations must be ascribed to withintype changes of circulation types. Except for April, they account for more than $50 \%$ of both temperature and precipitation changes. This dominance is most outstanding in July, with around $80 \%$.

Figures 5 and 7, showing monthly time series for the 1780-1995 period, depict additional differences between temperature and precipitation and between the four seasons in the importance of frequency and within-type changes of Central European Großwettertypes for the observed long-term climate changes. This appears more 

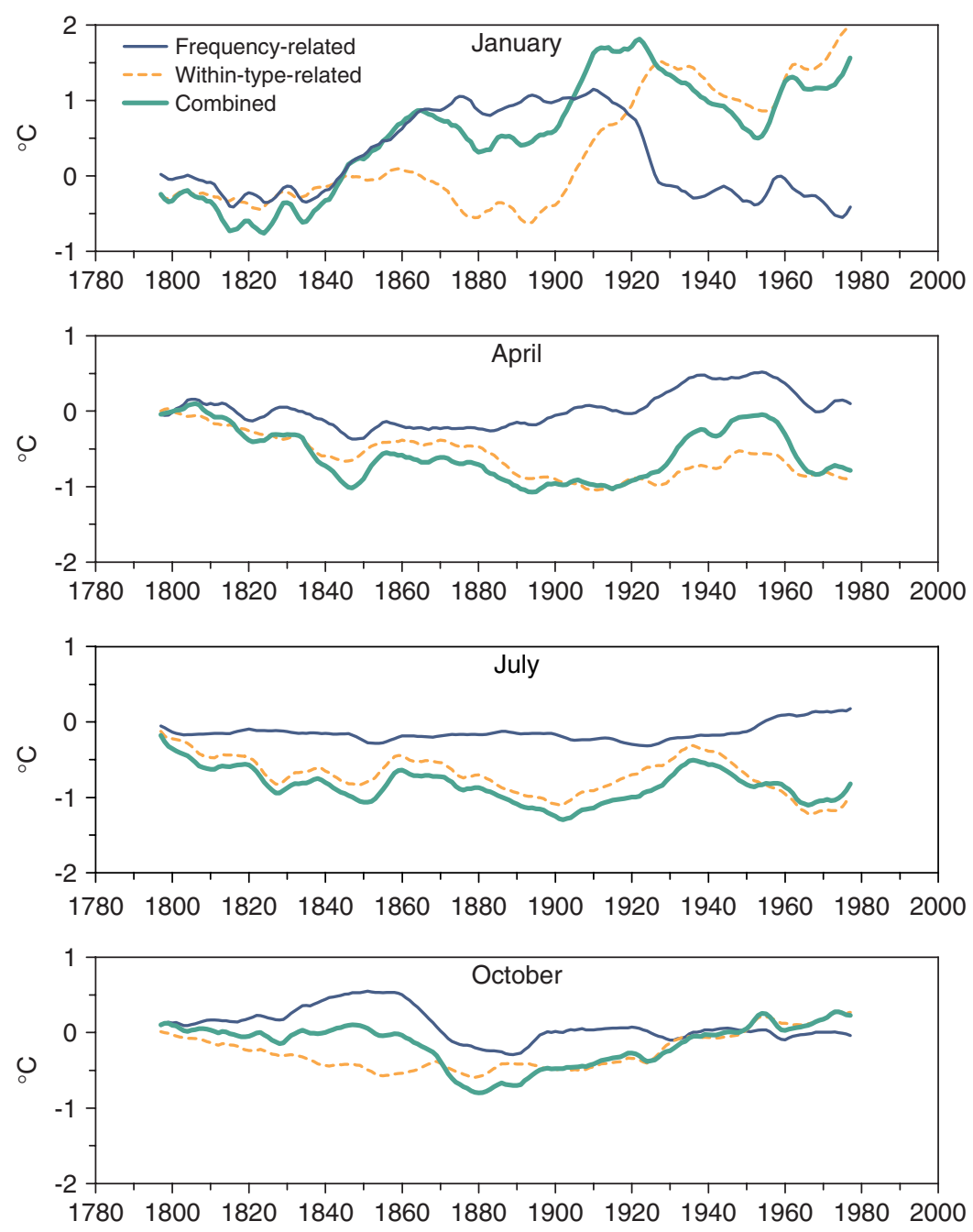

Figure 5. Cumulated Central European temperature differences between consecutive 31-year periods as well as those parts that can be ascribed to frequency changes and within-type changes of the large-scale circulation types from Figure 3 . This figure is available in colour online at www.interscience.wiley.com/ijoc

Table I. Percentages of the Central European temperature and precipitation variations in the 1780-1995 period due to frequency and within-type variations, respectively, of all large-scale Großwettertypes.

\begin{tabular}{lccccc}
\hline & \multicolumn{2}{c}{ Temperature } & & \multicolumn{2}{c}{ Precipitation } \\
\cline { 2 - 3 } \cline { 5 - 6 } & Frequency & Within-type & & Frequency & Within-type \\
\hline January & 46.8 & 53.2 & & 36.3 & 63.7 \\
April & 55.6 & 44.4 & & 54.4 & 45.6 \\
July & 17.9 & 82.1 & & 22.1 & 77.9 \\
October & 44.3 & 55.7 & & 44.7 & 55.3 \\
\hline
\end{tabular}

clear-cut in Figures 6 and 8. During all months, for temperature as well as for precipitation, there are distinct decadal to multidecadal variations differing from one case to the other. With the exception of July temperature and January precipitation, in which there is a prevailing dominance of within-type-related changes, all other cases show multiple shifts, during the whole 215 -year period, between frequency-related and within-type-related predominance in accounting for the decadal-scale climate variability in Central Europe.

January. Figures 5 and 6 show that the temperature variations in the late 18th century, until around 1860, are in accordance with the frequency changes of circulation types, whereas afterwards, except for the cooling period centred around 1930, within-type changes play the dominant role for Central European temperature variations. Specifically, the warming periods during the 20th century are largely due to these internal changes of circulation types.

For January precipitation, within-type-related variations are the predominant factor for nearly the whole period. However, since the 1920s, there is an obvious tendency that the increases in precipitation due to the withintype changes are markedly weakened by the increasing influence of frequency changes (Figures 7 and 8).

April. The marked long-term decrease in April temperature from the late 18th century until around 1900 is 

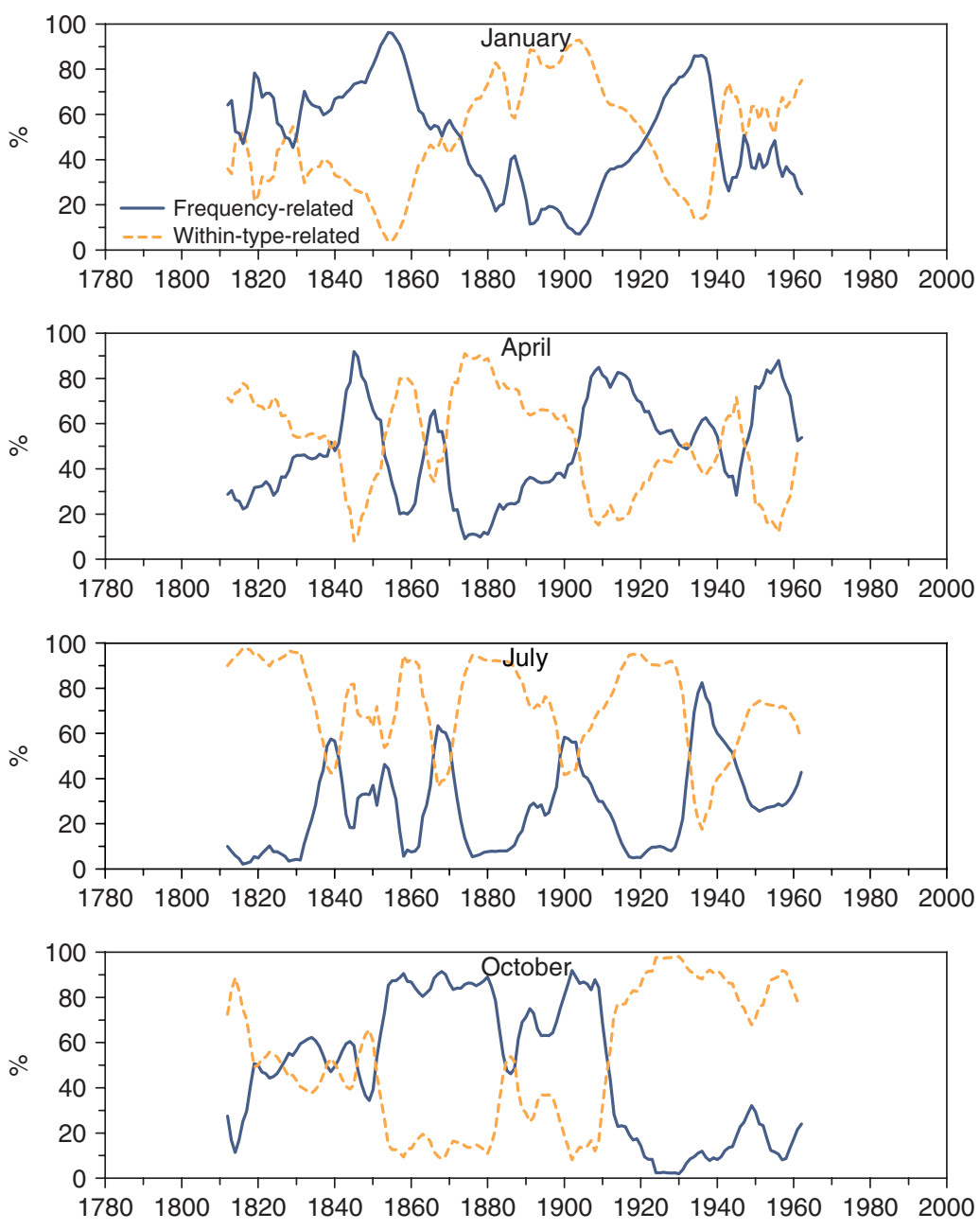

Figure 6. Percentages of the Central European temperature differences between consecutive 31-year periods that can be ascribed to frequency changes and within-type changes of the large-scale circulation types from Figure 3 . This figure is available in colour online at www.interscience.wiley.com/ijoc

likely related to within-type changes, whereas the subsequent temperature increase is mainly due to frequency changes of circulation types (Figures 5 and 6).

For April precipitation, periods with dominating influence of frequency changes are longer than those that are likely related to within-type changes (Figure 8). However, the latter also contribute substantially to the overall long-term positive trend in precipitation (Figure 7).

July. For July temperature variations, frequency changes of circulation types have only minor relevance (Figure 6). However, during the second half of the 20th century they still begin to provide a warming contribution before this becomes true for the within-type part (Figure 5).

For July precipitation, we recognize an alteration between periods with a distinct prevalence of within-type changes and shorter periods with moderate predominance of frequency changes (Figure 8). The sharp decline in precipitation since the mid-20th century starts with a frequency contribution before its recent acceleration due to within-type changes (Figure 7).
October. During the first half of the 19th century the opposite contributions of within-type and frequency changes resulted in nearly constant Central European temperatures (Figure 5). Afterwards, frequency changes dominated for several decades (Figure 6), including both for an initial cooling and a subsequent warming period. The later 20th century temperature increase was mainly due to within-type changes.

October precipitation reveals a distinct turning point around 1880 (Figure 7), marked decadal-scale variability in frequency-related and within-type-related percentages and opposite trends during the 20th century (Figure 8) - declining percentages for within-typerelated parts and increasing ones for frequency-related parts.

Up to now, results have focused on integrated effects of all Großwettertypes on Central European temperature and precipitation. The following sub-section will address particular Großwettertypes with special importance on the Central European context.

4.3.2. The influence of particular Großwettertypes. Table II gives the percentages of the entire temperature 

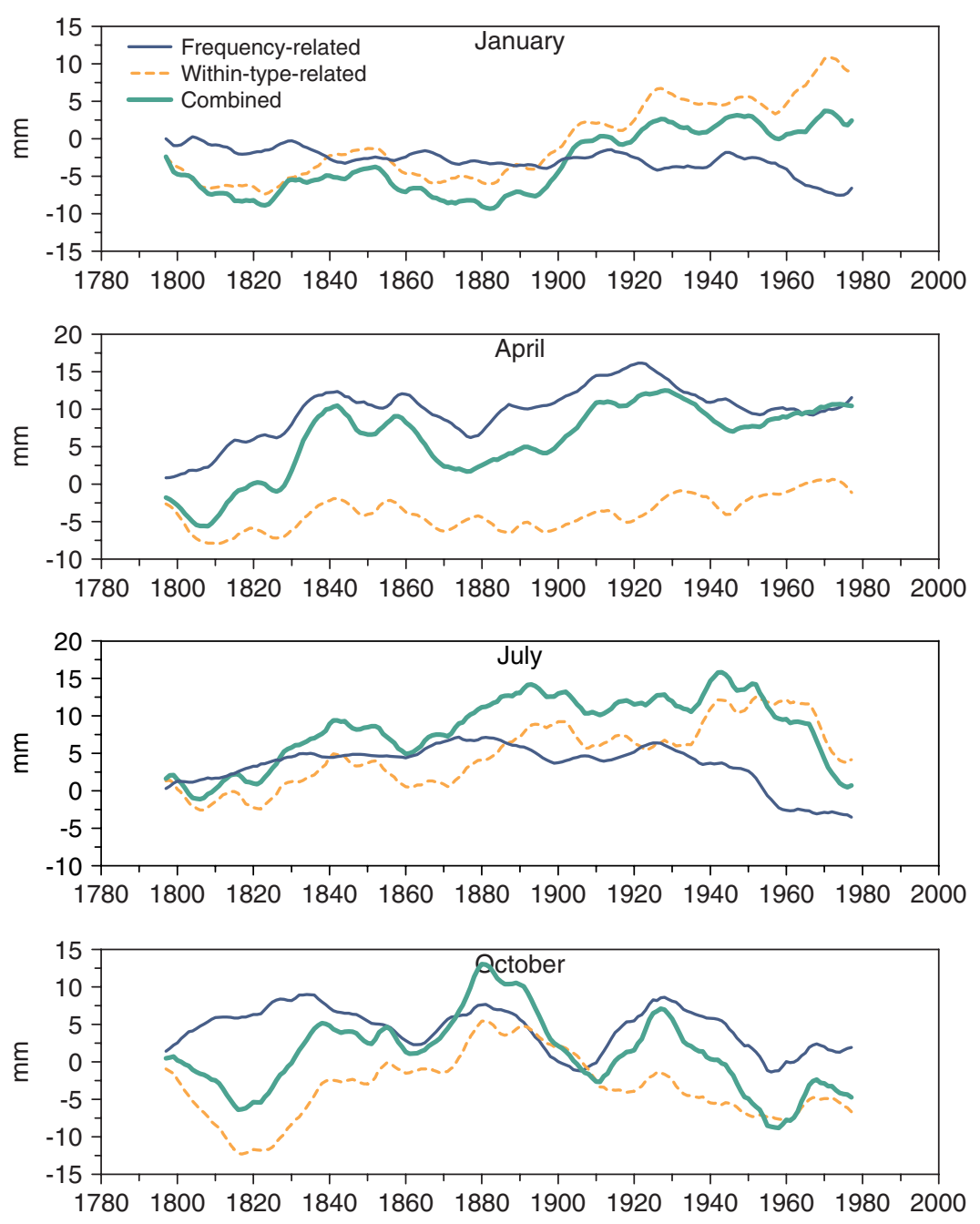

Figure 7. Same as Figure 5 but for precipitation. This figure is available in colour online at www.interscience.wiley.com/ijoc

and precipitation changes that can be attributed to the various circulation types during the 1780-1995 period. It clearly shows that large parts of the observed temperature and precipitation change are linked to a very limited number of circulation types. The most important ones, with respect to temperature as well as precipitation, in all the selected months are the westerly, southwesterly, and northwesterly types. Additionally, northerly types are somewhat important in July and southerly types in October.

Figures 9 to 12 provide the information (which was given for the ensemble of all Großwettertypes in Figures 5 and 7) individually for some of these important Großwettertypes; additionally, their observed variations in frequency and within-type characteristics are specified (climatic properties: Central European temperature and precipitation linked to the occurrence of the corresponding Großwettertype; dynamic properties: intensity and vorticity of this Großwettertype, see Section 3.2).

January. Großwettertype W accounts for $32.1 \%$ of January temperature variations between 1780 and 1995, this value is even larger for precipitation, at $41.0 \%$ (Table II). It plays a major part during the distinct
Table II. Percentages of the Central European temperature and precipitation variations due to variations in the 10 main large-scale Großwettertypes in the 1780-1995 period.

\begin{tabular}{|c|c|c|c|c|c|c|c|c|c|c|}
\hline \multicolumn{11}{|c|}{ Temperature } \\
\hline & $\mathrm{W}$ & SW & NW & $\mathrm{L}$ & $\mathrm{H}$ & $\mathrm{N}$ & $\mathrm{NE}$ & $\mathrm{E}$ & $\mathrm{SE}$ & $\mathrm{S}$ \\
\hline January & 32.1 & 26.3 & 3.8 & 1.2 & 2.5 & 0.3 & 1.4 & 3.3 & 16.3 & 12.7 \\
\hline April & 19.0 & 18.3 & 16.0 & 4.5 & 6.8 & 13.1 & 5.3 & 5.4 & 4.3 & 7.0 \\
\hline July & 13.1 & 0.0 & 63.0 & 0.0 & 6.5 & 16.8 & 0.6 & 0.0 & 0.0 & 0.0 \\
\hline October & 23.8 & 39.5 & 8.9 & 2.5 & 2.4 & 0.9 & 0.0 & 4.8 & 4.2 & 12.9 \\
\hline \multicolumn{11}{|c|}{ Precipitation } \\
\hline & $\mathrm{W}$ & SW & NW & $\mathrm{L}$ & $\mathrm{H}$ & $\mathrm{N}$ & $\mathrm{NE}$ & $\mathrm{E}$ & SE & $\mathrm{S}$ \\
\hline January & 41.0 & 29.4 & 6.1 & 0.0 & 5.5 & 0.9 & 0.3 & 1.5 & 4.7 & 10.7 \\
\hline April & 26.1 & 10.0 & 18.0 & 5.5 & 10.7 & 8.7 & 5.4 & 6.0 & 3.9 & 5.9 \\
\hline July & 17.4 & 0.0 & 63.9 & 0.0 & 2.9 & 15.3 & 0.4 & 0.0 & 0.0 & 0.0 \\
\hline October & 31.5 & 33.7 & 5.1 & 2.0 & 6.8 & 0.6 & 0.0 & 0.3 & 2.4 & 17.5 \\
\hline
\end{tabular}

rise in temperature and precipitation (Figure 2) from the late 19th to the early 20th century: according to Figure 9(a), both quantities arising from this circulation 

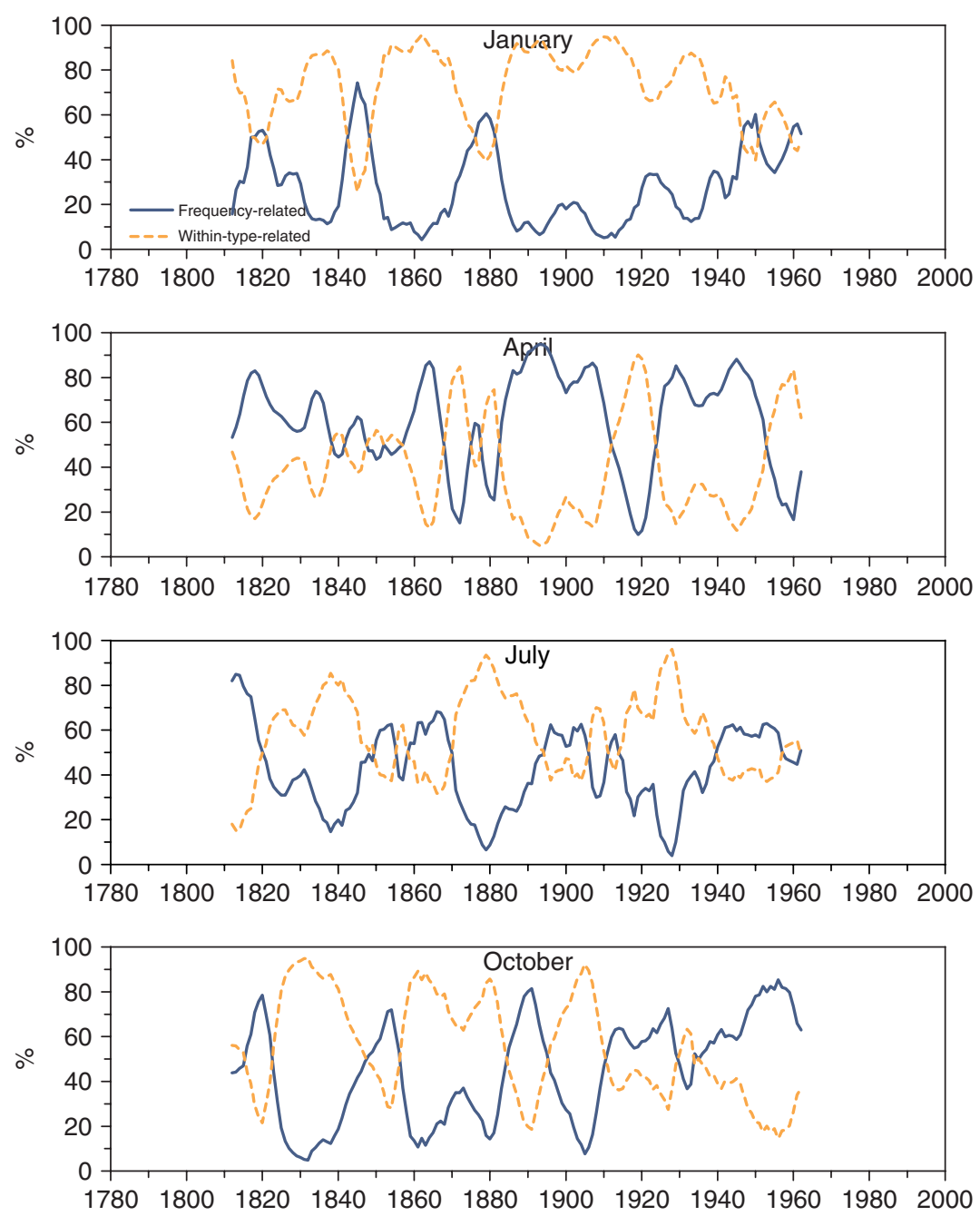

Figure 8. Same as Figure 6 but for precipitation. This figure is available in colour online at www.interscience.wiley.com/ijoc

type increase during this time due to corresponding within-type changes (increasing values of the circulationtype-related indices for intensity, vorticity, temperature, and precipitation). However, the earlier warming period during the mid-19th century (Figure 2) was mainly due to Großwettertype SW, especially to its marked increase in frequency around this time (Figure 9(b)). Despite its subsequent decrease in frequency, SW additionally contributed to the second warming period mentioned above owing to its increase in within-type parameters during the early 20th century (Figure 9(b)).

Additionally, the long-term upward trend in January temperatures and precipitation totals are further supported by corresponding developments of Großwettertype S (Figure 9(c)), whose within-type parameters are mostly seen to rise since around 1820. Finally, Großwettertype SE (Figure 9(d)) contributes indirectly to the long-term positive trend in Central European January temperatures since the mid-19th century: it showed a long-term decline in frequency, thus reducing the occurrence of its typical conditions of below-normal winter temperatures in Central Europe. The cooling that followed after $\sim 1930$ (Figure 2), however, was again primarily due to within-type changes of W and SW (Figure 9): decreasing values of circulation-type-related indices for temperature and intensity, at first for W, one decade later for SW.

April. Großwettertype W, one of the most important types for climate variations in April (Table II), accounts for the distinct changes during the first half of the 19th century (temperature decrease combined with rainfall increase, see Figure 2). This was essentially realised by within-type changes, in particular, an increase in vorticity concomitant with corresponding changes in precipitation (increasing) and temperature (decreasing) linked with the occurrence of this circulation type (Figure 10(a)). Additionally, Großwettertype SW (Figure 10(c)) contributed to the declining April temperatures by decreasing frequencies and its own reduced temperatures.

The next period of distinct climate change of April during the first half of the 20th century (starting with a rainfall increase followed by a warming interval, see Figure 2) is linked with different mechanisms. Rising precipitation is mostly due to Großwettertype W, the most important one for April rainfall variations (Table II), at this time operating by increased frequency as well as slightly rising vorticity. The subsequent temperature 
(a)
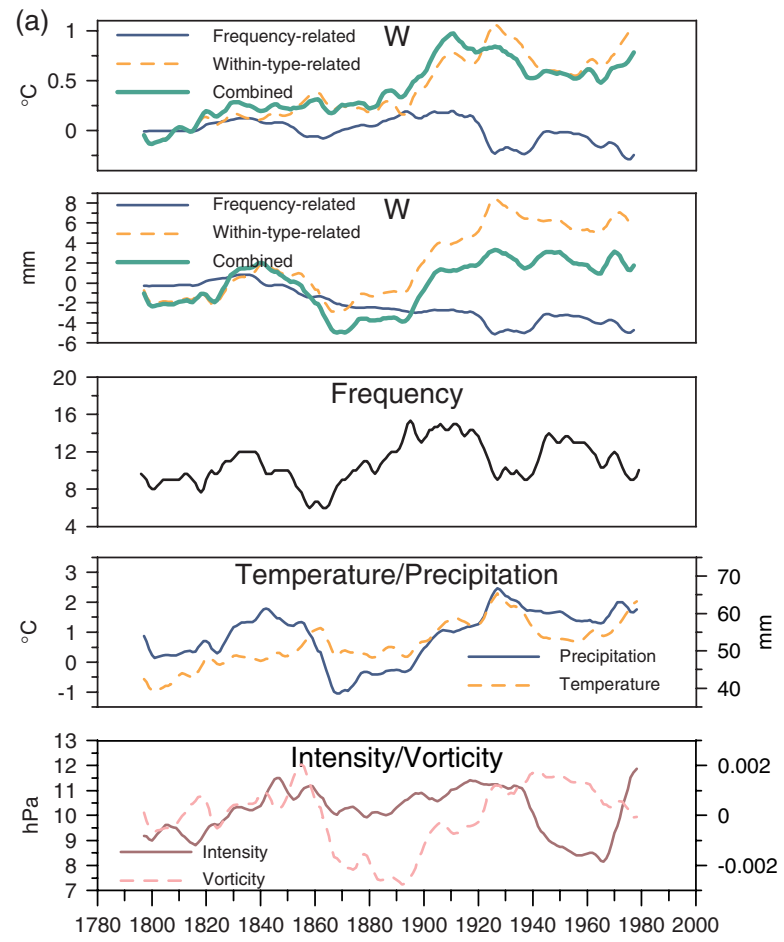

(c)
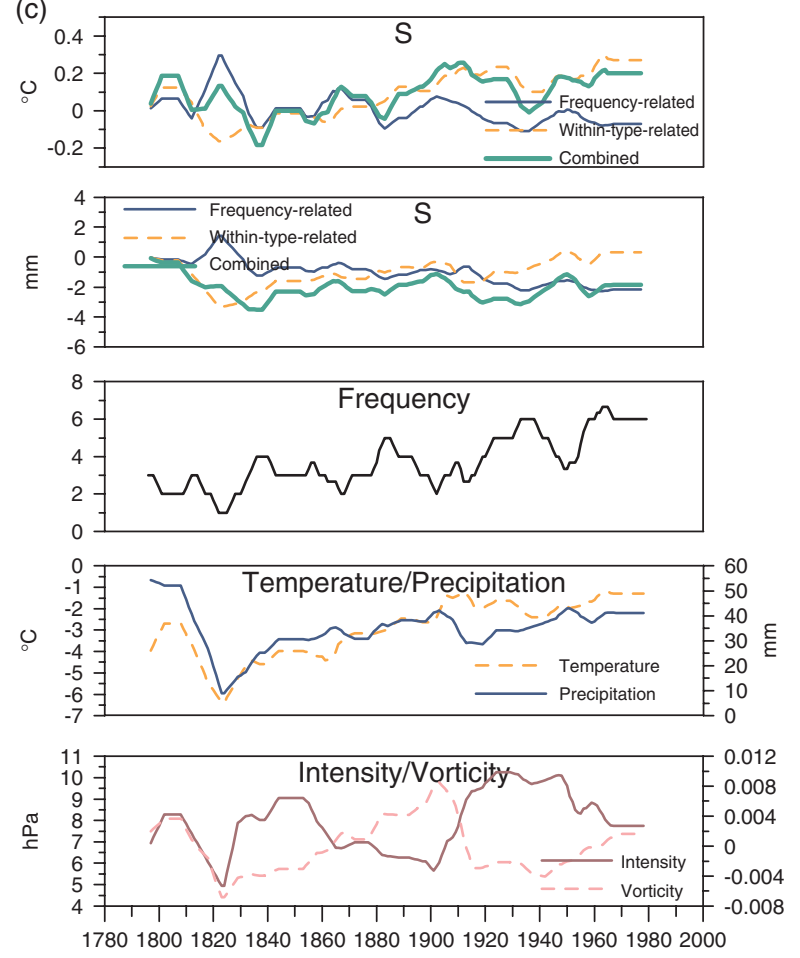

(b)
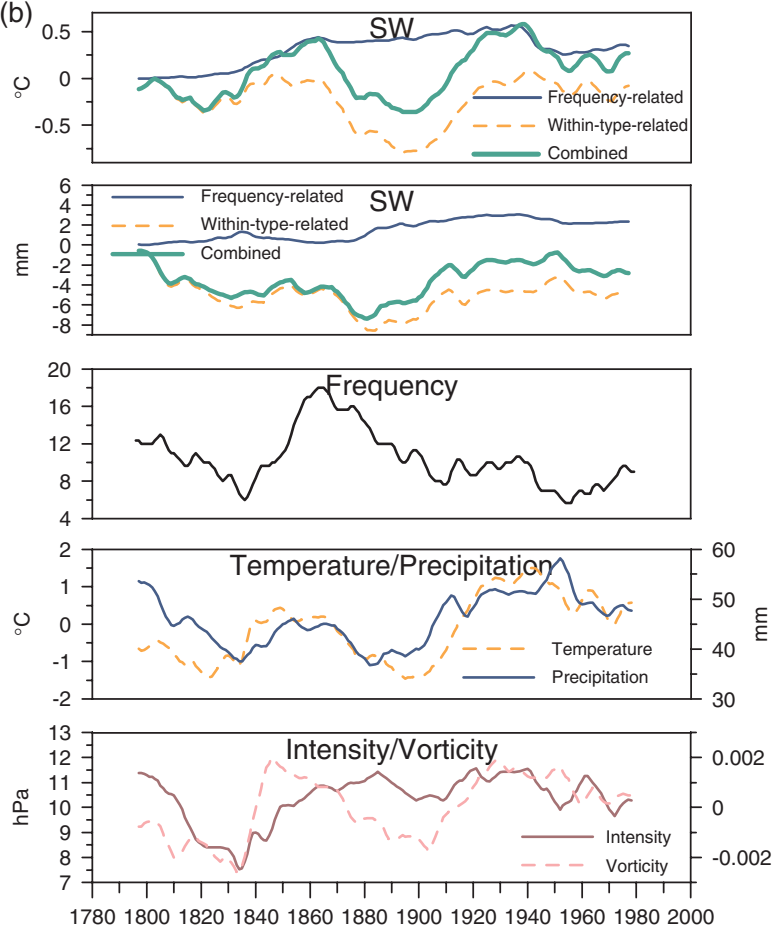

(d)
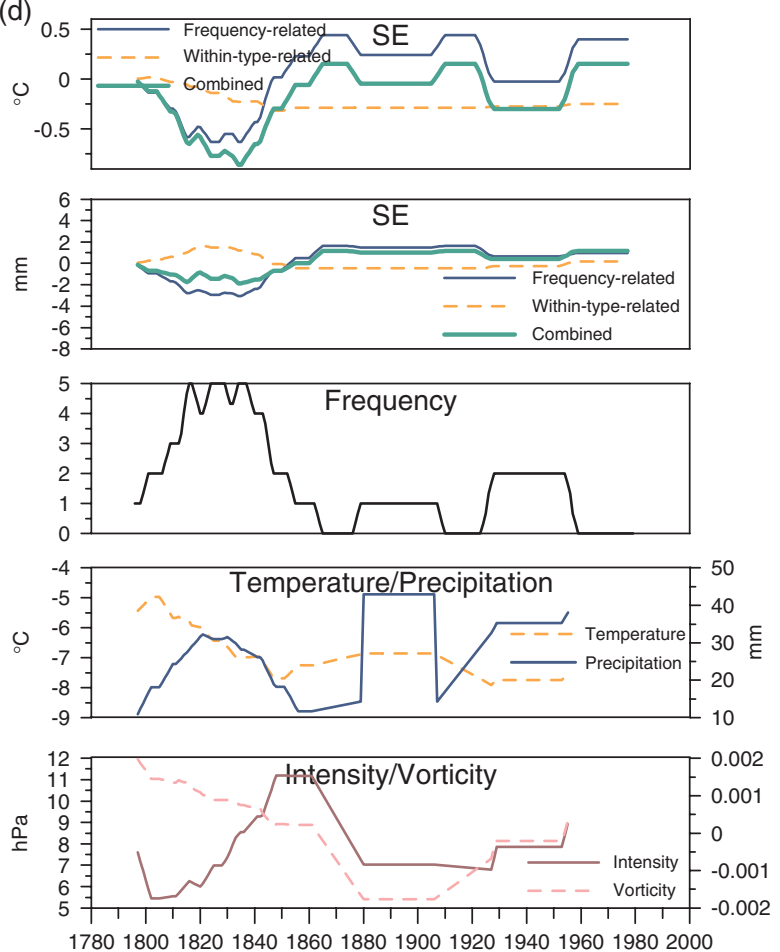

Figure 9. (a)-(d) Upper two panels in each quarter: Cumulated Central European January temperature and precipitation differences between consecutive 31-year periods that can be ascribed to a particular circulation type, to its frequency changes, and to its within-type changes. Third to fifth panels in each quarter: Frequency and within-type changes (see Section 3.2 for definitions) of the corresponding circulation type. This figure is available in colour online at www.interscience.wiley.com/ijoc

increase is mainly due to increasing within-type temperatures and rising frequencies of Großwettertype $\mathrm{W}$ (Figure 10(a)), supported by within-type warming of SW (Figure 10(c)) and NW (Figure 10(b)).

The latter type also accounts for the longer-term tendencies of decreasing temperature and increasing precipitation between the 1850 s and 1920 s, primarily due to its rising trend in vorticity (Figure 10(b)). A further contribution during this period comes from lowering frequencies of the anticyclonic Großwettertype $\mathrm{H}$ (Figure 10(d)).

July. Climatic variations during July are primarily linked with Großwettertype NW, accounting for $63.0 \%$ 

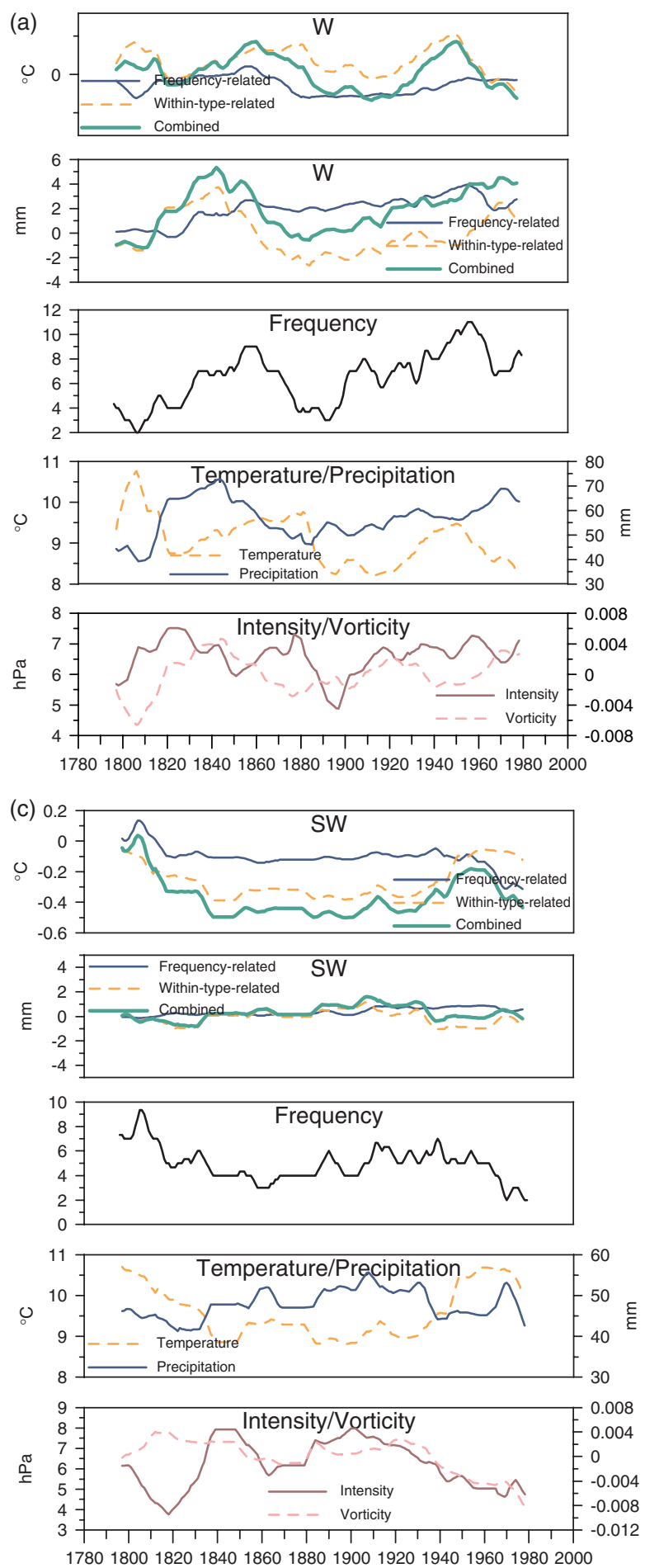
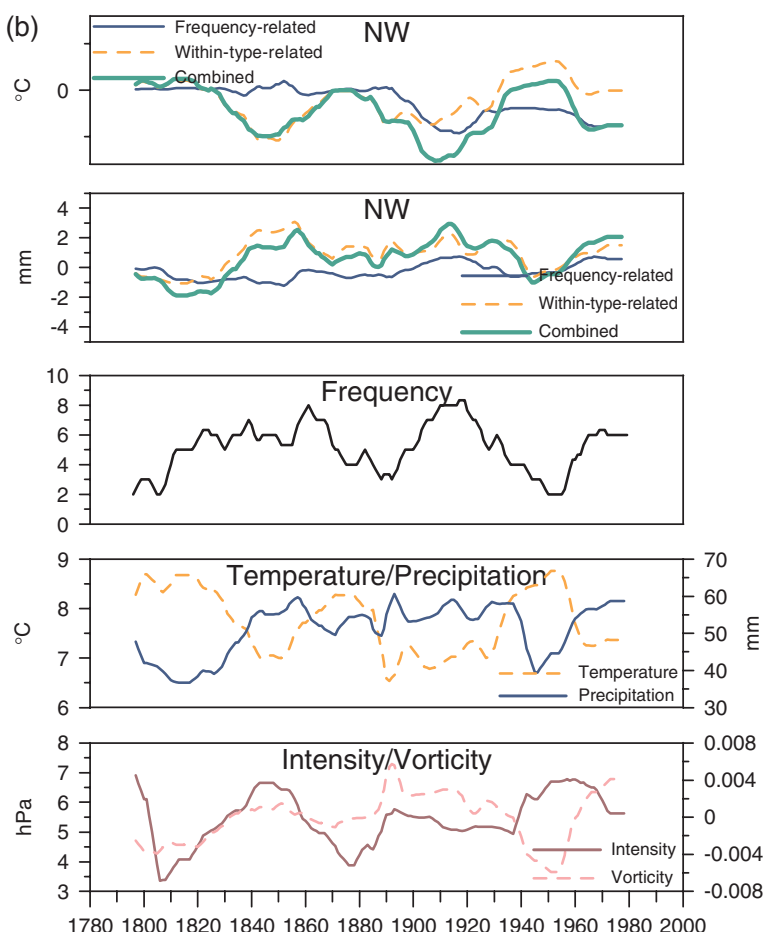

(d)
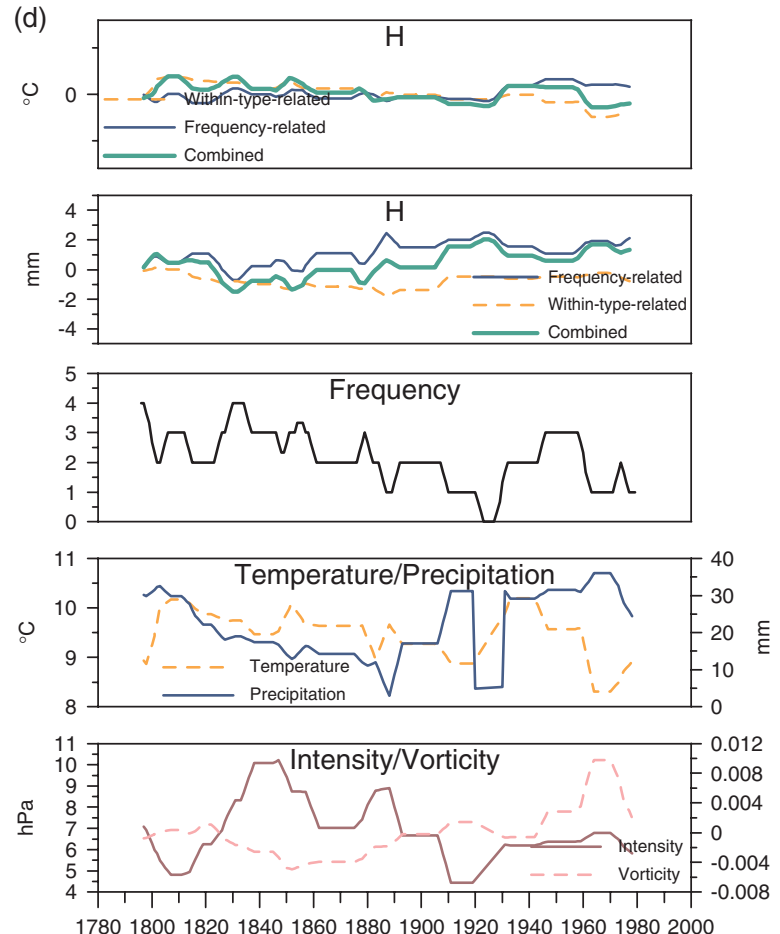

Figure 10. (a)-(d), same as Figure 9, but for April. This figure is available in colour online at www.interscience.wiley.com/ijoc

and $63.9 \%$ of temperature and rainfall variations in Central Europe, respectively (Table II). Thus, the temporal developments of these variables (Figure 2) recur in Figure 11(a) with respect to circulation-type-related temperature and precipitation. In contrast to within-type changes, frequency changes are of minor importance, but they mostly act in the same sense, thus somewhat amplifying the integrated NW effect. The anti-phase relationship of decreasing temperature with increasing rainfall and vice versa comes to an end by the mid-20th century, both for NW-related indices (Figure 11(a)) as well as for the Central European climate in general (Figure 2). As for NW, this refers to the late change to recent warming being attributable to a preceding secondary vorticity maximum. With Figure 2, this refers to an early rainfall decrease after 1950 being attributable to decreasing frequencies as well as within-type precipitation of Großwettertype W (Figure 11(b)). The concomitant cooling was less developed than expected from NW since Großwettertype N (Figure 11(c)) increased in 
(a)
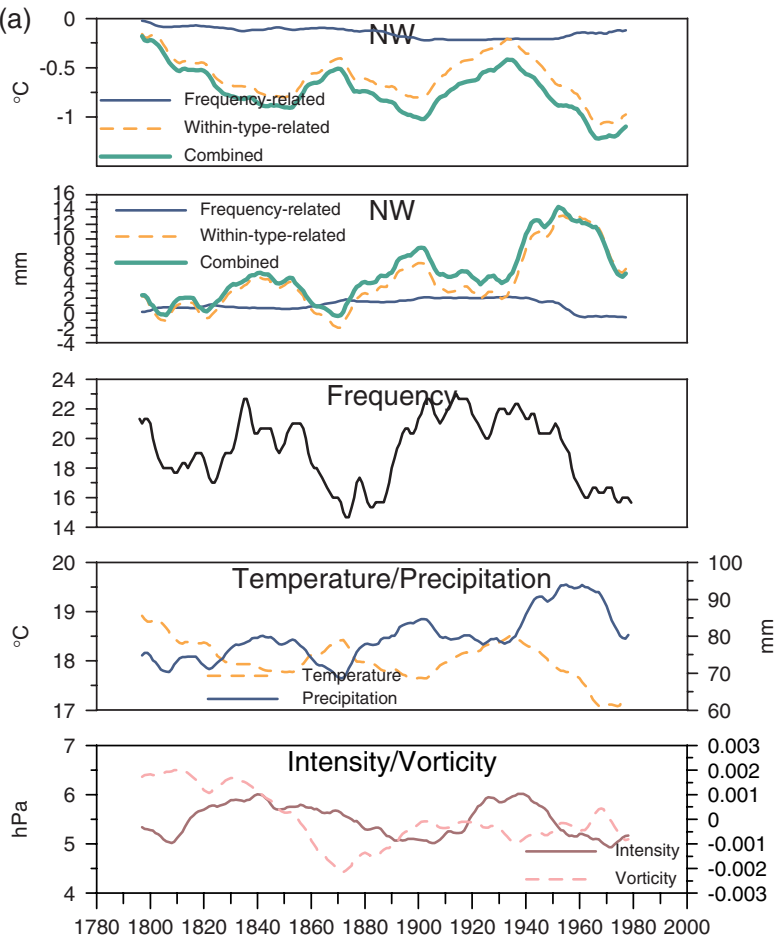

(b)
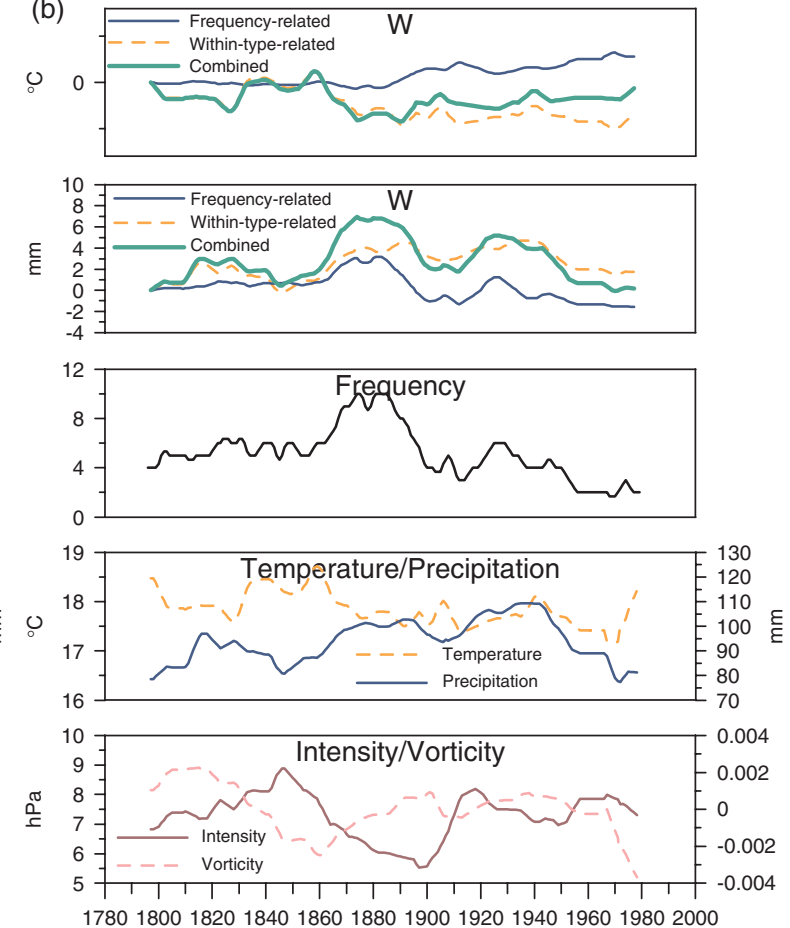

(c)
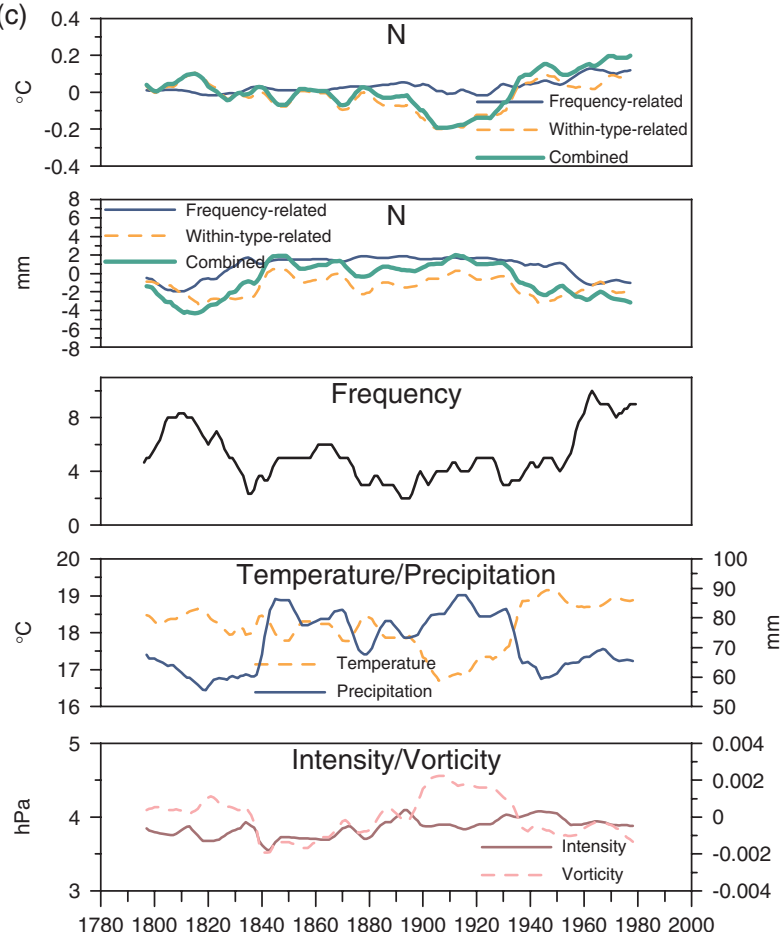

Figure 11. (a)-(c), same as Figure 9, but for July. This figure is available in colour online at www.interscience.wiley.com/ijoc

frequency and maintained a high temperature level. The prior period experienced substantial long-term changes in $\mathrm{N}$ vorticity (increasing during the second half of the 19th century, decreasing afterwards), but their climatic effects remained secondary owing to low frequencies of $\mathrm{N}$ (Figure 11(c)).

October. The most important Großwettertypes for climate variations in Central Europe during this month are SW and W, accounting for between 23.8 and $39.5 \%$
(Table II) of the variance. Their long-term frequencies develop in an opposite manner from around 1860 (oscillatory decrease/increase for SW/W, see Figure 12). Central European temperatures decline during the 1860-1880 period and slowly rise thereafter (Figure 2), which is largely due to the SW-related temperature indices that generally covary with SW intensity (Figure 12(a)). The declining frequencies of this circulation type would lead to a slight temperature decrease, which is, however, 
(a)
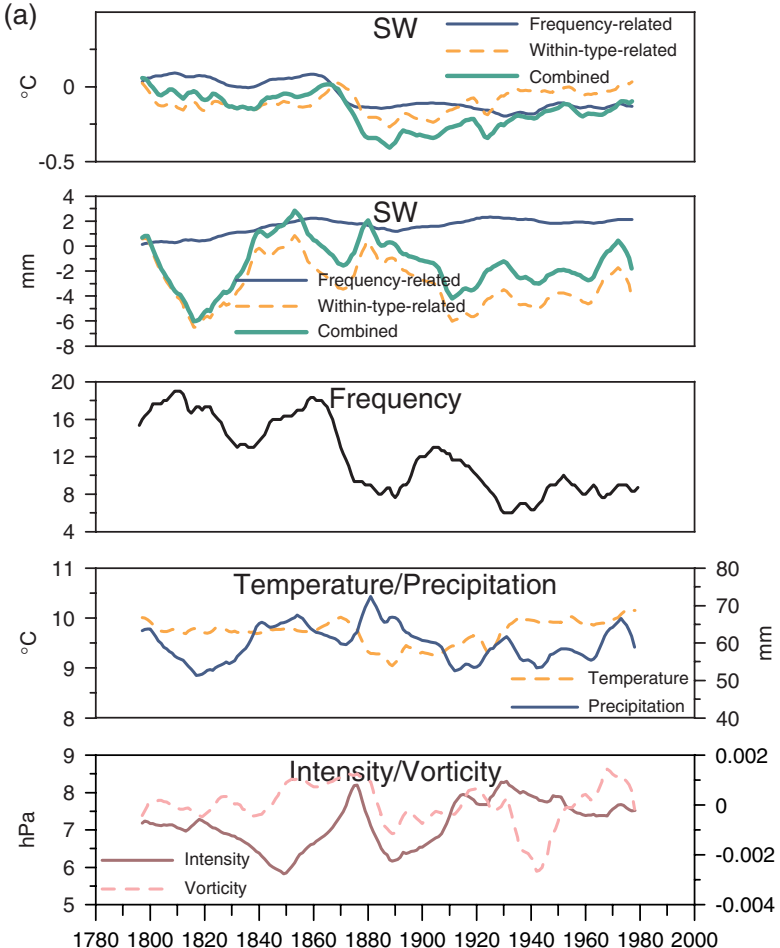

(b)
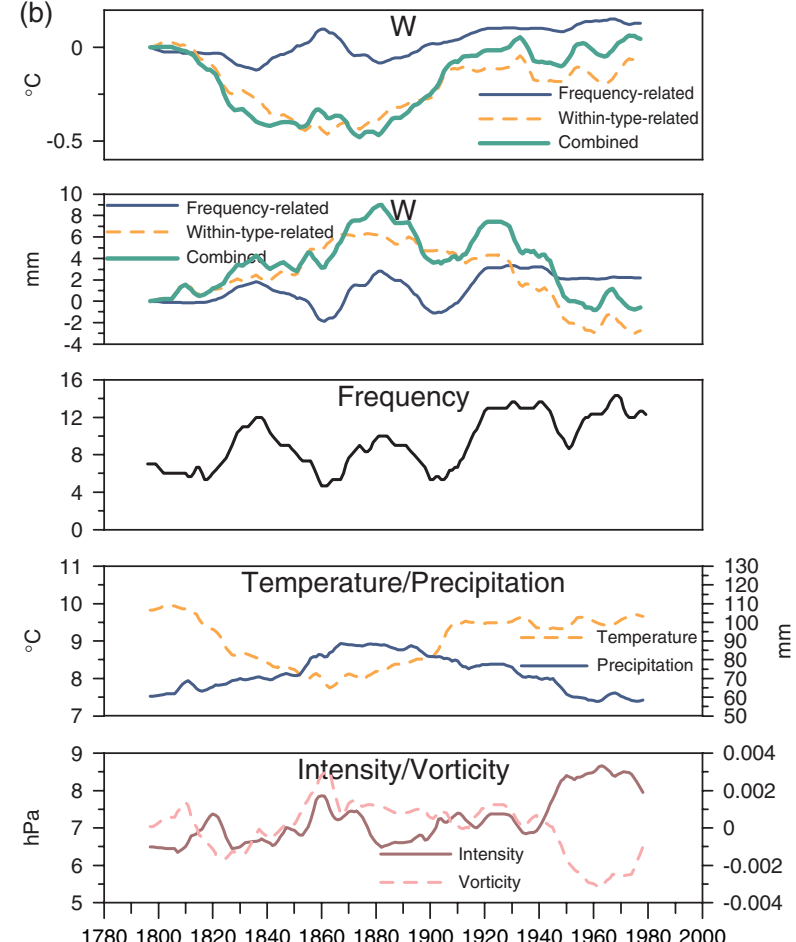
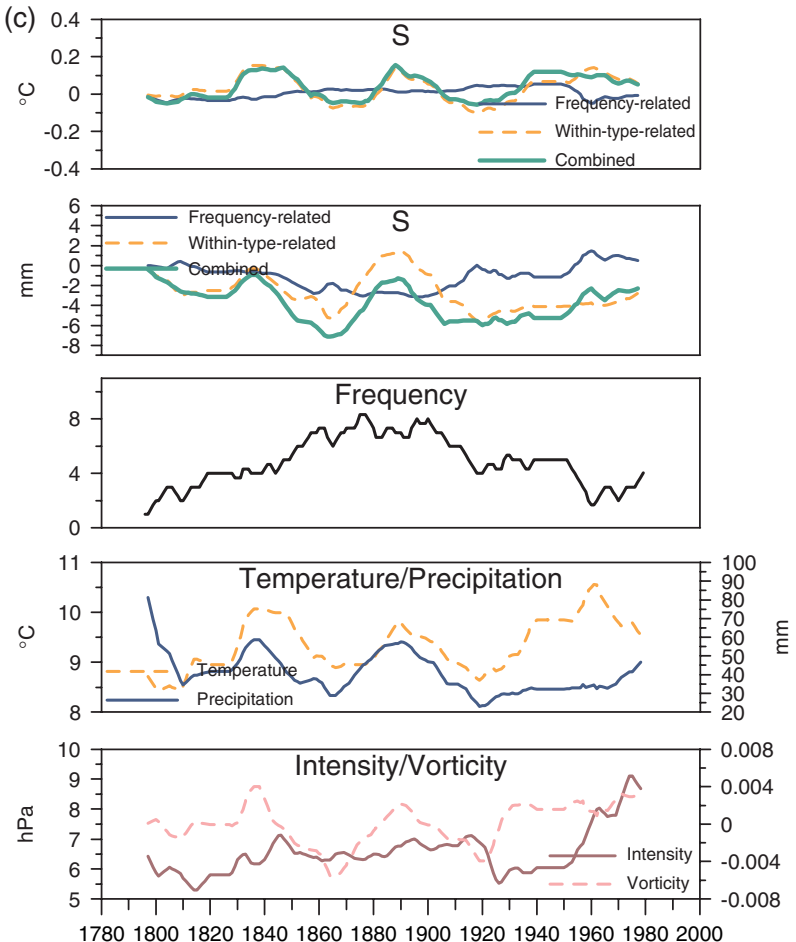

Figure 12. (a)-(c), same as figure 9, but for October. This figure is available in colour online at www.interscience.wiley.com/ijoc

overcompensated during the 20th century by the withintype warming of SW. A somewhat earlier temperature increase is due to the inclusion by Großwettertype $\mathrm{W}$ of a frequency-related contribution and slowing down in its within-type part during the 20th century (Figure 12(b)).

Rainfall conditions in Central Europe are marked by various minima and maxima, the most outstanding occurs around 1880 (Figure 2). It is due to several influences: a broad peak of rainfall contribution from
$\mathrm{W}$, including frequency-related and within-type-related parts (Figure 12(b)), a smaller peak from SW exclusively caused by within-type deviations (Figure 12(a)), and finally an additional effect arising mainly from increasing vorticity of S (Figure 12(c)). Further, rainfall maxima and minima from Figure 2 recur in the SW-related precipitation indices, reflecting within-type changes that are in general accordance with the vorticity parameter (Figure 12(a)). 


\section{DISCUSSION AND CONCLUSIONS}

This study focussed on the importance of frequency and within-type changes of atmospheric circulation types for Central European climate variations during the last two centuries. Varying internal characteristics of circulation modes are a major factor in synoptic climatology (Barry and Perry, 1973) and have been investigated for different regional domains, e.g. North America (Brinkmann, 1999), the British Isles (Perry and Barry, 1973), and Scandinavia (Chen, 2000; Linderson, 2001). For the European region, this topic was addressed with several approaches: Beck (2000) referred to particular periods in comparison (1780-1860 and 1915-1995), Jacobeit et al. (2001a) identified various 30-year periods since 1780 with different composites for the same circulation patterns, Beck et al. (2001) and Jacobeit et al. (2003) revealed continuous changes of dynamic and climatic properties within major atmospheric circulation modes. The major advancement of the present study is the direct link to regional climate variations for a period of more than 200 years. Central European temperature and precipitation changes have been decomposed into two parts; one part is due to frequency changes of large-scale atmospheric circulation types, and the other part is caused by (dynamic and climatic) changes within these circulation types. This was achieved by applying a particular decomposition scheme (Barry and Perry, 1973) to historical station data for climate (Jacobeit et al., 1998) and to an objective classification, into Großwettertypes (Beck, 2000), of reconstructed monthly mean SLP grids back to 1780 (Jones et al., 1999b).

Reliability of results depends directly on the reconstruction quality of the SLP data set, which is highest for the central grid points and decreases towards the peripheral regions, in particular, during the early decades of the study period (Jones et al., 1999b). Therefore, it is a great advantage in this investigation that circulation typing and vorticity estimation are based exclusively on central grid points of the SLP data set. Only the estimation of the intensity indices partly includes peripheral grid points. Thus, temporal intensity variations may partly be biased by constraints of the marginal SLP data during the early reconstructed decades.

A major outcome from this study is that large parts of the low-frequency variations in Central European climate cannot be explained sufficiently by varying frequencies of circulation types, roughly one half of these variations - even up to $80 \%$ during July - have to be ascribed to varying internal properties of some major circulation types (mainly NW in summer, $\mathrm{W}$ and $\mathrm{SW}$ during the other seasons). The actual percentages of frequencyrelated and within-type-related climate changes are varying not only between seasons and variables but also in each case - on decadal to multidecadal time scales. This means that relationships between large-scale atmospheric circulation patterns and regional climates are characterised by substantial non-stationarities, which should be considered in every kind of downscaling approaches that are used for transferring such relationships to periods with changed boundary conditions for the atmosphere.

Furthermore, those parts of regional climate variations that are due to within-type changes of major circulation types can only partly be derived from corresponding variations in dynamic properties (vorticity, intensity) of these circulation types. Remaining parts may originate from different sources, including the following important ones: (1) subgrid-scale phenomena, like orographically induced rainy systems, not being resolved by the reconstructed SLP grids ( $5^{\circ}$ latitude by $10^{\circ}$ longitude), (2) synoptic-scale variations that cannot be resolved with monthly mean data, such as variations in persistence and transition frequencies of major circulation types, and (3) variations in climatic boundary conditions affecting areas from which advection takes place for particular circulation types. North Atlantic SST variations are a prominent example for which Jones et al. (1999a) have shown a significant correlation with temperatures on the Scilly Isles on days with Lamb weather types, implying advection from SW to NW. Those parts of the within-type variations in temperature and precipitation (Figures 9-12) that are unexplained by dynamical parameters of the corresponding circulation types should include substantial contributions of source area boundary conditions to the resulting variations in Central European climate - objectives that have to be analysed in forthcoming studies.

In the context of recent global warming during the last decades, one might suspect that there should be a systematic increase in percentages of within-type changes due to changed climatic boundary conditions in response to enhanced greenhouse forcing of the climate system. However, results have shown that there is no significant trend in this direction, i.e. the particular ways that the increased forcing by greenhouse gases (Houghton et al., 2001) seems to affect both frequency and withintype changes are yet to be investigated in more detail. Concerning the attribution of observed variations to manmade climate change, such advanced analyses would require particular model studies.

At this stage, we have an objective identification of the influence of frequency and within-type changes of major circulation types on Central European climate on a time scale that substantially exceeds reanalyses periods of roughly half a century. The study period of more than two centuries allowed obtaining results in varying circulation-climate relationships that would not have been possible on the basis of periods of only a few decades. Therefore, the objective of reconstructing gridded fields of circulation parameters back into historical times is important for extended analyses on dynamic climatology.

\section{ACKNOWLEDGEMENTS}

Most part of this work was supported by a Postdoc Scholarship of the German Research Association DFG 
(grant BE 2406/1), SLP grids back to 1780 were reconstructed during the EU-project ADVICE (ENV4-CT950129) entering as a reference into the EU-project EMULATE (EVK2-CT-2002-00161).

\section{REFERENCES}

Alexandersson H. 1986. A homogeneity test applied to precipitation data. J. Climatol. 6: 661-675.

Bardossy A, Caspary HJ. 1990. Detection of climate change in Europe by analyzing European circulation patterns from 1881 to 1989 . Theoretical and Applied Climatology 42: 155-167.

Barnston AG, Livezey RE. 1987. Classification, seasonality and persistence of low frequency atmospheric circulation patterns. Monthly Weather Review 115: 1083-1126.

Barry RG, Perry AH. 1973. Synoptic Climatology. Methuen: London.

Beck C. 2000. Zirkulationsdynamische Variabilität im Bereich Nordatlantik-Europa seit 1780. Würzburger Geographische Arbeiten 95. Geographisches Institut: Würzburg.

Beck C, Jacobeit J, Philipp A. 2001. Variability of North AtlanticEuropean Circulation Patterns since 1780 and corresponding variations in Central European Climate. In Detecting and Modelling Regional Climate Change, Brunet India M, Lopez Bonillo D (eds). Springer Verlag: Berlin; 321-332.

Böhm R. 1992. Description of the procedure of homogenizing temperature time series in Austria. Middle European Research Initiative, Project Group Meteorology, Working Paper 2. Central Institute for Meteorology and Geodynamics: Vienna.

Brinkmann WAR. 1999. Within-type variability of $700 \mathrm{hPa}$ winter circulation patterns over the Lake Superior Basin. International Journal of Climatology 19: 41-58.

Chen D. 2000. A monthly circulation climatology for Sweden and its application to a winter temperature case study. International Journal of Climatology 20: 1067-1076.

Corte-Real J, Wang X, Zhang X. 1995. Large-scale circulation regimes and surface climatic anomalies over the mediterranean. International Journal of Climatology 15: 1135-1150.

Dittmann E, Barth S, Lang J, Müller-Westermeier G. 1995. Objektive Wetterlagenklassifikation. Berichte des Deutschen Wetterdienstes 197. Deutscher Wetterdienst: Offenbach/Main.

El-Kadi AKA, Smithson PA. 1992. Atmospheric classifications and synoptic climatology. Progress in Physical Geography 16: 432-455.

Frakes B, Yarnal B. 1997. A procedure for blending manual and correlation-based synoptic classifications. International Journal of Climatology 17: 1381-1396.

Gerstengarbe FW, Werner PC. 1993. Katalog der Großwetterlagen Europas nach Paul Hess und Helmuth Brezowski 1881-1992. Berichte des Deutschen Wetterdienstes 113. Deutscher Wetterdienst: Offenbach/Main.

Glaser R. 1991. Klimarekonstruktion für Mainfranken, Bauland und Odenwald Anhand Direkter und Indirekter Witterungsdaten Seit 1500. Fischer: Stuttgart.

Glaser R. 2001. Klimageschichte Mitteleuropas: 1000 Jahre Wetter, Klima, Katastrophen. Wissenschaftliche Buchgesellschaft: Darmstadt.

Hess P, Brezowski H. 1952. Katalog der Großwetterlagen Europas. Berichte des Deutschen Wetterdienstes in der US-Zone 33. Deutscher Wetterdienst in d. US-Zone: Bad Kissingen.

Huth R. 1996. An intercomparison of computer-assisted circulation classification methods. International Journal of Climatology 16: 893-922.

Houghton JT, Ding Y, Griggs DJ, Noguer M, van der Linden PJ, Dai X, Maskell K, Johnson CA (eds). 2001. Climate Change 2001: The Scientific Basis. Cambridge University Press: Cambridge.

Jacobeit J. 1993. Regionale Unterschiede im atmosphärischen Zirkulationsgeschehen bei globalen Klimaveränderungen. Die Erde 124: $63-77$.

Jacobeit J, Beck C, Philipp A. 1998. Annual to decadal variability in Climate in Europe - objectives and results of the German contribution to the European climate research project ADVICE. Würzburger Geographische Manuskripte 43. Geographisches Institut: Würzburg.

Jacobeit J, Wanner H, Koslowski G, Gudd M. 1999. European surface pressure patterns for months with outstanding climatic anomalies during the sixteenth century. Climatic Change 43: 201-221.

Jacobeit J, Jones PD, Davies TD, Beck C. 2001a. Circulation changes in Europe since the 1780s. In History and Climate: Memories of the
Future? Jones PD, Ogilvie A, Davies TD, Briffa KR (eds). Kluwer Academic Publishers: New York; 79-99.

Jacobeit J, Jönsson P, Bärring L, Beck C, Ekström M. 2001b. Zonal indices for Europe 1780-1995 and running correlations with temperature. Climatic Change 48: 219-241.

Jacobeit J, Wanner H, Luterbacher J, Beck C, Philipp A, Sturm K. 2003. Atmospheric circulation variability in the North AtlanticEuropean area since the mid-seventeenth century. Climate Dynamics 20: $341-352$.

Jones PD, Wigley TML, Wright PB. 1987. Monthly mean pressure reconstructions for Europe (back to 1780) and North-America (to 1858). US Department of Energy: Washington DC; DOE Technical Report No. TR 037.

Jones PD, Hulme M. 1996. Calculating regional climatic time series for temperature and precipitation: methods and illustrations. International Journal of Climatology 16: 361-377.

Jones PD, Horton EB, Folland CK, Hulme M, Parker DE, Basnett TA. 1999a. The use of indices to identify changes in climatic extremes. Climatic Change 42: 131-149.

Jones PD, Davies TD, Lister DH, Slonosky VC, Jonsson T, Bärring L, Jönsson P, Maheras P, Kolyva-Maheras F, Barriendos M, MartinVide J, Rodriguez R, Alcoforado MJ, Wanner H, Pfister C, Luterbacher J, Rickli R, Schuepbach E, Kaas E, Schmith T, Jacobeit J, Beck C. 1999b. Monthly mean pressure reconstruction for Europe for the 1780-1995 period. International Journal of Climatology 19: 347-364

Kapala A, Mächel H, Flohn H. 1998. Behaviour of the centres of action above the atlantic since 1881. Part II: associations with regional climate anomalies. International Journal of Climatology 18: 23-26.

Kington J. 1988. The Weather of the 1780s Over Europe. Cambridge University Press: Cambridge.

Kirchhofer W. 1973. Classifications of European $500 \mathrm{mb}$ patterns. Arbeitsbericht der Schweizerischen Meteorologischen Zentralanstalt 43. Schweizerische Meteorologische Zentralanstalt: Zürich.

Klaus D. 1997. Anderungen der Zirkulationsstruktur im europäischatlantischen Sektor. Akademie der Wissenschaften und der Literatur Abhandlungen der Mathematisch-Naturwissenschaftlichen Klasse 3. Steiner: Stuttgart.

Kruizinga S. 1979. Objective classification of daily 500 mbar patterns. Preprints Sixth Conference on Probability and Statistics in the Atmospheric Sciences, 9-12. October, Banff, Alberta. American Meteorological Society: Boston, MA; 126-129.

Lamb HH. 1950. Types and spells of weather around the year in the British Isles: annual trends, seasonal structure of years, singularities. Quarterly Journal of the Royal Meteorological Society 76: 393-438.

Lamb HH, Johnson AI. 1959. Climatic variation and observed changes in the general wind circulation: parts I and II. Geografiska Annaler 41: $94-134$.

Lamb HH, Johnson AI. 1961. Climatic variation and observed changes in the general wind circulation: part III. Geografiska Annaler 43 $363-400$.

Linderson ML. 2001. Objective classification of atmospheric circulation over southern Scandinavia. International Journal of Climatology 21: $155-169$.

Lund IA. 1963. Map-pattern classification by statistical methods. Journal of Meteorology 2: 56-65.

Luterbacher J, Rickli R, Xoplaki E, Tinguely C, Beck C, Pfister C, Wanner H. 2001. The late maunder minimum (1675-1715) - a key period for studying decadal scale climate change in Europe. Climatic Change 49: 441-462.

Luterbacher J, Xoplaki E, Dietrich D, Rickli R, Jacobeit J, Beck C, Gyalistras D, Schmutz C, Wanner H. 2002a. Reconstruction of Sea level pressure fields over the Eastern North Atlantic and Europe back to 1500. Climate Dynamics 18: 545-561.

Luterbacher J, Xoplaki E, Dietrich D, Jones PD, Davies TD, Portis D, Gonzalez-Rouco JF, von Storch H, Gyalistras D, Casty C, Wanner H. 2002b. Extending North Atlantic Oscillation reconstructions back to AD 1500. Atmospheric Science Letters 2: 114-124.

Mächel H, Kapala A, Flohn H. 1998. Behaviour of the centres of action above the atlantic since 1881. Part I: characteristics of seasonal and interannual variability. International Journal of Climatology 18: $1-22$.

Perry AH, Barry RG. 1973. Recent temperature changes due to changes in the frequency and average temperature of weather types over the British Isles. Meteorological Magazine 102: 73-82.

Pfister C. 1985. Klimageschichte der Schweiz 1525-1860-Bd. 2 Verlag Paul Haupt: Bern.

Pfister C. 1999. Wetternachhersage. 500 Jahre Klimavariationen und Naturkatastrophen 1496-1995. Verlag Paul Haupt: Bern. 
Rogers JC. 1997. North Atlantic storm track variability and its association to the North Atlantic Oscillation and climate variability of Northern Europe. Journal of Climate 10: 1635-1647.

Schmutz C, Wanner H. 1998. Low frequency variability of atmospheric circulation over Europe between 1785 and 1994. Erdkunde 52: 81-94.

Schönwiese CD, Rapp J. 1997. Climate Trend Atlas of Europe - Based on Observations 1881-1990. Kluwer Academic Publishers: Dordrecht.

Wanner H, Brazdil R, Frich P, Frydendahl K, Jonsson T, Kington J, Pfister C, Rosenorn S, Wishman E. 1994. Synoptic interpretation of monthly weather maps for the late Maunder Minimum (1675-1704).
In Climatic Trends and Anomalies in Europe 1675-1715, Frenzel B (ed.). Fischer: Stuttgart; 401-424.

Werner PC, von Storch H. 1993. Interannual variability of Central European mean temperature in january-february and its relation to large scale circulation. Climate Research 3: 195-207.

Werner PC, Gerstengarbe FW, Fraedrich K, Oesterle H. 2000. Recent climate change in the North Atlantic/European sector. International Journal of Climatology 20: 463-471.

World Climate Disc. 1992. Global climate change data. Climatic Research Unit. University of East Anglia: Norwich.

Yarnal B. 1993. Synoptic Climatology in Environmental Analysis. Belhaven Press: London. 